\title{
Genome-wide association study and its applications in the non-model crop Sesamum indicum
}

\author{
Muez Berhe ${ }^{1,2+}$, Komivi Dossa ${ }^{1,3,4^{*}+}$, Jun You' ${ }^{1}$ Pape Adama Mboup ${ }^{5}$, Idrissa Navel Diallo ${ }^{3,5}$, Diaga Diouf ${ }^{3}$, \\ Xiurong Zhang ${ }^{1}$ and Linhai Wang ${ }^{1 *}$
}

\begin{abstract}
Background: Sesame is a rare example of non-model and minor crop for which numerous genetic loci and candidate genes underlying features of interest have been disclosed at relatively high resolution. These progresses have been achieved thanks to the applications of the genome-wide association study (GWAS) approach. GWAS has benefited from the availability of high-quality genomes, re-sequencing data from thousands of genotypes, extensive transcriptome sequencing, development of haplotype map and web-based functional databases in sesame.

Results: In this paper, we reviewed the GWAS methods, the underlying statistical models and the applications for genetic discovery of important traits in sesame. A novel online database SiGeDiD (http://sigedid.ucad.sn/) has been developed to provide access to all genetic and genomic discoveries through GWAS in sesame. We also tested for the first time, applications of various new GWAS multi-locus models in sesame.
\end{abstract}

Conclusions: Collectively, this work portrays steps and provides guidelines for efficient GWAS implementation in sesame, a non-model crop.

Keywords: GWAS, Sesame, Statistical models, Genomics assisted breeding

\section{Background}

Sesame (Sesamum indicum L, $2 \mathrm{n}=2 \mathrm{x}=26$ ) which belongs to the Pedaliaceae family is one of the most ancient oilseed crops domesticated from the wild progenitor S. malabaricum in Near East, Asia and Africa over 5,000 years ago $[1,2]$. Sesame is reputed for its climate-resilience, high oil content, and unique antioxidant

\footnotetext{
*Correspondence: dossakomivi@gmail.com; linhai827@163.com

${ }^{\dagger}$ Muez Berhe and Komivi Dossa contributed equally to this work.

1 Oil Crops Research Institute of the Chinese Academy of Agricultural

Sciences, Key Laboratory of Biology and Genetic Improvement of Oil Crops, Ministry of Agriculture, and Rural Affairs, No.2 Xudong 2nd Road, Wuhan 430062, China

${ }^{4}$ Laboratory of Genetics, Horticulture and Seed Sciences, Faculty

of Agronomic Sciences, University of Abomey-Calavi, 01 BP 526, Cotonou,

Republic of Benin

Full list of author information is available at the end of the article
}

properties [3]. It is an important source of high-quality edible oil and protein food. The oil content of sesame seed ranges from $50-60 \%$ with a high proportion of natural antioxidants such as sesamolin, sesamin, and sesamol, conferring a long shelf life and stability to the oil $[4,5]$. Ashakumary et al. [6] reported that sesame seed contains $19-25 \%$ protein and is a good source of iron, magnesium, copper, calcium, vitamins B1, E and phytosterols that help to lower the levels of blood cholesterol. Besides, all essential amino acids and fatty acids are present in the sesame seed [7]. The sesame sector is a billion-dollar industry that supports the livelihoods of millions of farmers throughout the world [8]. The total production has significantly increased over the last ten years, reaching 6 million tons in 2017 (Food and Agriculture Organization Statistical Database [9]. Sesame production and 
productivity, however, face different constraints, including limited numbers of improved varieties, shattering of capsules at maturity, non-synchronous maturity, poor stand establishment, profuse branching, low harvest index, drought stress, waterlogging and diseases [10-12]. To accelerate sesame improvement, genomics assisted breeding has been adopted as an efficient approach for developing superior varieties in a short time [13]. Hence, the reference genome sequence of sesame together with numerous essential genomic resources was delivered to the scientific community [14]. The haplotype map of the sesame genome was constructed from a re-sequencing project of 705 worldwide diverse cultivars and two representative genomes were further de novo assembled [15]. These resources are vital to the quick advancement of sesame research, as they expedite the detection of genetic loci that control important agronomic traits using the genome-wide association study (GWAS) approach. Today, hundreds of causative genetic variants associated with important traits such as oil quality, abiotic stress resistance, seed yield have been discovered. These findings facilitate the use of marker-assisted selection and genomic selection to advance genetic improvement and overall productivity of sesame. This makes sesame a rare case of non-model and minor crop for which genomic studies, particularly GWAS, have been very successful.

In this review paper, we first present the GWAS approach and underlying statistical models. Then, the ongoing efforts of genetic discovery through applications of GWAS in sesame are presented in detail. We conclude this paper with important guidelines for better applications of GWAS in sesame.

\section{Main text \\ GWAS approach, underlying statistical models and applications in plants GWAS approach}

Genome-wide association study (GWAS) also known as association mapping or linkage disequilibrium (LD) mapping takes the full advantage of high phenotypic variation within a species and the high number of historical recombination events in the natural population. It has become an alternative approach over the conventional quantitative trait locus (QTL) mapping to identify the genetic loci underlying traits at a relatively high resolution [15]. GWAS in general is applicable to study the association between single-nucleotide polymorphisms (SNPs) and target phenotypic traits. Nowadays, SNP identification is becoming much easier using advanced high throughput genotyping techniques. GWAS, quantitatively is evaluated based on LD by genotyping and phenotyping various individuals in a natural population panel. Unlike the traditional QTL mapping approach, which makes the use of bi-parental segregating populations, identification of causal genes for traits of interest in GWAS is performed in natural populations. A key advantage of GWAS is that the same genotyping data and the same population can be used over and over for different traits.

GWAS has been successfully applied to identify associations at a high resolution, detect candidate genes and dissect the quantitative traits in human, animals, and plants $[16,17]$. GWAS in various economically valuable crops has been used to gain insight into the genetic architecture of important traits, including days to heading, days to flowering panicle architecture, resistance to rice yellow mottle virus, fertility restoration, and agronomic traits in rice [18-21]; pattern of genetic change and evolution [22, 23], compositional and pasting properties [24], stalk biomass [25] and leaf cuticular conductance [26] in maize; plant height components and inflorescence architecture [27], grain size [28] and grain quality [29] in sorghum; harvest index in maize [30], flowering time in canola [31], stress tolerance, oil content and seed quality [32] in brassica; oil yield and quality [15], yield related traits [33, 34], drought tolerance [35], vitamin E [36] in sesame.

\section{Statistical models underlying GWAS approach Single-locus models}

Marker-trait association using GWAS has been widely detected using one-dimensional genome scans of the population [19, 37-39]. In this method, one SNP is evaluated at a time. Following the use of general linear model (GLM) which is described as $\mathbf{Y}=\boldsymbol{\beta}_{\mathbf{0}}+\boldsymbol{\beta}_{\mathbf{1}} \mathbf{X}$ [40] (where $\mathrm{Y}$ $=$ dependent/predicted/ explanatory/response variable, $\boldsymbol{\beta}_{\mathbf{0}}=$ the intercept; $\boldsymbol{\beta}_{\mathbf{1}}=\mathrm{a}$ weight or slope (coefficient); $\mathbf{X}$ $=\mathrm{a}$ variable), a popular model referred as a Mixed Linear Model (MLM) ( $\mathrm{Q}+\mathrm{K}$ method) which is described as $\mathbf{Y}=$ $\mathbf{X} \boldsymbol{\beta}+\mathbf{Z u}+\mathbf{e}$ [41], (where $\mathbf{Y}=$ vector of observed phenotypes; $\boldsymbol{\beta}=$ unknown vector containing fixed effects, including the genetic marker, population structure $(\mathrm{Q})$, and the intercept; $\mathbf{u}=$ unknown vector of random additive genetic effects from multiple background QTL for individuals/lines; $\mathbf{X}$ and $\mathbf{Z}=$ known design matrices; and $\mathbf{e}=$ unobserved vector of residuals) was developed to control the multiple testing effects and bias of population stratification in GWAS. Then, the accuracy of association mapping has been reported partially improved $[17,42,43]$. Subsequently, numerous advanced statistical methods based on the MLM have also been suggested to resolve certain limitations such as false-positive rates, large computational consequences, and inaccurate predictions [44]. Efficient mixed model association (EMMA) [45], compressed mixed linear model (CMLM) and population parameters previously determined (P3D) [46], and random-SNP-effect mixed linear model (MRMLM) 
[47] are some of the latest improved single-locus genome scans MLM-based approaches proposed so far. Such advanced statistical models are powerful, flexible, and computationally efficient. EMMA was proposed to minimize the computational load exhibited in the MLM probability functions by considering the quantitative trait nucleotide (QTN) effect as a fixed effect [17, 44, 45]; while CMLM was proposed to control the size of huge genotype data by grouping individuals into groups and, thus, the group kinship matrix is derived from the clustered individuals [46]. Generally, despite its limitation for efficient estimation of marker effects in complex traits, the single-locus model approach has a good ability to handle several markers [47], and this is one of its worthy reported features.

Although the single-locus model analysis was a common approach for association analysis between each SNP and phenotype in GWAS, some earlier reports suggested that the use of a single-locus model analysis has limitations to resolve potential effects caused by multiple tests, historical genotype effects and pleiotropic effects [17, 48]. They reported that the interaction between the available genetic variants throughout the genome is not profoundly explored when only on SNP is tested at a time. Similarly, the Bonferroni correction employed to control the false-positive error (FDR) due to multiple testing is also very stringent in this approach, hence significant numbers of important loci may not be identified by the single-locus models particularly for large errors due to phenotypic data and multi-locus effects $[49,50]$. Thus, it has been suggested that these single-locus genome scan methods are not convenient to test quantitative traits regulated by a few and/or many genes with large and minor effects, respectively $[17,49]$. Besides, the genetic epistatic effects generated within close genes could not be explored in single-locus methods [51].

\section{Haplotype-based models}

To address some of the limitations in the single-locus model analysis, haplotype-based models, which is conducted based on a random SNP effect mixed linear model (MRMLM) described as: $\mathbf{Y}=\mathbf{X} \boldsymbol{\beta}+\mathbf{Z}_{\mathbf{k}} \mathbf{y}_{\mathbf{k}}+\mathbf{u}+\mathbf{e}$ (where $\mathbf{Y}=$ a vector of estimated genotypic value for all lines is an incident matrix for fixed effects as population structure, $\boldsymbol{\beta}$ is a vector of the fixed effect, $\mathbf{Z}_{\mathbf{k}}=$ a vector of genotype indicators for $k^{\text {th }}$ SNP, $\mathbf{Y}_{\mathbf{k}}=$ random effect of marker $\mathrm{k}$ with $\sim \mathrm{N}\left(0, \mathrm{~K}^{2}{ }_{\mathrm{k}}\right), \mathbf{u}=$ vector of polygenic effects described by the kinship matrix $(\mathrm{K})$ with $\sim \mathrm{N}(0$, $\left.\sigma^{2}{ }_{\mathrm{a}}\right)$ and $\mathbf{e}=$ vector of residuals errors with $\sim \mathrm{N}\left(0, \mathrm{I} \sigma_{\mathrm{e}}^{2}\right)$ ), was developed and implemented for some major crops such as wheat, rice, and soybean $[52,53]$. Several neighboring markers in high LD are clustered into a single multi-locus haplotype in this multivariate method, thus the haplotypes are evaluated in a multiple GLM system rather than individual SNPs, and the associations between the haplotypes and the traits under selection have been observed [48, 52, 54]. The haplotype-based model is relatively more efficient and reliable than the traditional single-locus models in GWAS as it helps to accurately capture the allelic diversity, optimize the use of high-density marker data, enhance the power of epistatic interactions discovery and minimize multiple testing $[51,52]$.

\section{Multi-locus models}

Multi-locus models are newly developed alternative methods in GWAS involving two-stage algorithms [55-57] consisting of a single locus scan of the entire genome to detect all possible associated SNPs (QTNs) and then testing all associated SNPs using a multi-locus GWAS model to detect true QTNs. These newly developed multi-locus GWAS models are ideal for testing complex quantitative traits regulated by multiple genes/ loci and less influenced by population structure. Some advantages of multi-locus models over single-locus models are for example, the detection of multiple genes governing a given trait with high power and efficiency, low false-positive rate and no need of Bonferroni correction for multiple testing known to potentially exclude important loci $[17,47,58,59]$. Multi-locus models have also resulted in substantial improvements of the quality and depth of the association results in GWAS [17, $42,53,57,60,61]$. The models currently largely implemented in GWAS include a multi-locus mixed model (MLMM) [57], multi-locus random SNP-effect mixed linear model (mrMLM) [47], integrative sure independence screening expectation-maximization Bayesian least absolute shrinkage and selection operator model (ISIS EM-BLASSO) [50], fast multi-locus random-SNP-effect efficient mixed model association (FASTmrEMMA) [17], polygene-background-control-based least angle regression plus Empirical Bayes (pLARmEB) [62], Kruskal-Wallis test with empirical Bayes under polygenic background control (pKWmEB) [58] and fast multi-locus randomSNP-effect mixed linear model (FASTmrMLM) [59, 63]. Among the numerous multi-locus models recorded to date, Segura et al. [57] proposed a MLMM method which has an advantage over other existing multi-locus methods, including penalized logistical regression [64], Stepwise regression [65], Bayesian-inspired penalized maximum likelihood, computational efficiency, false discovery rate detection and addressing the problems of population structure in GWAS. Similarly, Korte et al. [66] also proposed a mixed model method referred to as a multi-trait mixed model (MTMM) that detects the causal loci for precisely correlated multiple phenotype 
traits and simultaneously deals with both intra-trait and inter-trait variance components. Likewise, Klasen et al. [61] suggested a Quantitative Trait Cluster Association Test (QTCAT) analysis of multi-locus associations without employing population correction techniques and this model showed better results in limiting the false positive/negative associations due to correction strategies to mitigate confounding impacts. Multi-Trait Analysis of GWAS (MTAG) was also another specific approach developed by Turley et al. [67] to analyze summary statistics (meta-analysis) in GWAS. Zhan et al. [68] also proposed another method, named Dual Kernel Association Test (DKAT) that includes two individual kernel matrices to explain phenotype and genotype similarities. Some of DKAT's advantages over existing methods include being able to test the relationship between multiple traits and multiple SNPs without making parametric assumptions, correcting Type I error rates, being statistically highly efficient and computationally scalable [60, 68].

Recently, different comparative studies have been conducted to assess the capacity of these different GWAS models in detecting marker-trait associations in different plant species. Globally, it has been found that the multilocus models were more efficient and powerful than the single-locus models to detect highly significant association results for the traits of interest (Table 1). However, integrating both single-locus and multi-locus models have been proved to enhance the power and validity of the association analysis of complex traits in GWAS because single-locus models could detect some loci that multi-locus models fail to identify $[54,70]$.

\section{Use of pan-genome vs single reference genome for GWAS}

The common approach to study a given population's genetic variation relies on the interpretation of genes and variants annotated from the sequences of the existing reference genome [74]. Currently, reference genome sequences of many crops, including rice [75-77], sorghum [78], maize [79], Brassica rapa [80], barely [81, 82], millet [83], potato [84], tomato [85], and sesame [14] have been reported. Following the generation of highquality reference genome sequences, several GWAS have been carried out to discover the natural variation among diverse populations. However, the reference-genomebased GWAS approach may not be sufficient to distinguish any difference between or within the population in which certain relevant genes may be inactive in the reference genome but may be expressed in the studied populations [86].

Since the discovery of pan-genome in Streptococcus agalactiae [87], different pan-genomes have been constructed through comparison of multiple genomes derived from de novo sequences assembly of various individuals of the same species including, rice [88, 89], maize [90]), soybean [91], B. napus [92], wheat [93] and recently in sesame [94] (Table 2). Unlike the reference genome sequencing-based GWAS approach which depends on SNPs among the entire panel under investigation, the pan-genome approach is more inclusive and could detect copious variation including structural variation (SV), copy number variation (CNV), present/absent variation, inversion and translation variations $[30,86]$. In this regard, Song et al. [96] reported a direct detection of causal structural variation for the target traits (silique length, seed weight and flowering time) in Brassica napus based on the PAV-based genome-wide association study (PAV-GWAS) using the pan-genome assembled from eight high-quality genomes. They also reported that the SNP-GWAS approach that involves the single reference genome indicated no detection of causal structural variation for the same population. The result of their study indicates that the pan-genome based association study is a powerful approach that can complement the singlereference genome approach in detecting new SNP-trait associations. Likewise, the physical position of the sugarcane mosaic virus resistance gene $(Z m T r x h)$ in maize was discovered using a pan-genome assembled from three different genotypes, but not with the use of the single reference genome [90]. Other pan-genomes based GWAS have been conducted in important crops such as rice and pigeon pea $[89,97]$.

\section{Diversity and development of GWAS populations in sesame \\ Morphological and genetic diversity}

Sesame is a diploid species and belongs to the division Spermatophyta, subdivision Angiospermae, class Dicotyledoneae, order Tubiflorae, family Pedaliaceae, and genus Sesamum. Pedaliaceae is a small family of 16 genera and 60 species of which 37 species belong to Sesamum genus and only Sesamum indicum L. is the most commonly cultivated species [10, 39, 98-100]. A high number of varieties and ecotypes are reported with high adaptation to various ecological conditions in the world. There are three cytogenetic groups in Sesamum of which $2 \mathrm{n}=26$ consists of the cultivated $S$. indicum along with S. alatum, S. capense, S. schenckii, $S$. malabaricum; $2 \mathrm{n}=32$ consists of $S$. prostratum, $S$. laciniatum, S. angolense, S. angustifolium; while $S$. radiatum, $S$. occidentale and $S$. schinzianum belong to $2 \mathrm{n}=64$ [101-103]. So far, extensive morphological variations including plant height, height to the first capsule, height to first branch, number of branches, flowering period, flower color, number of flowers per axil, number of capsule per axil, capsule edge number days to maturity, number of seeds per capsule, number 


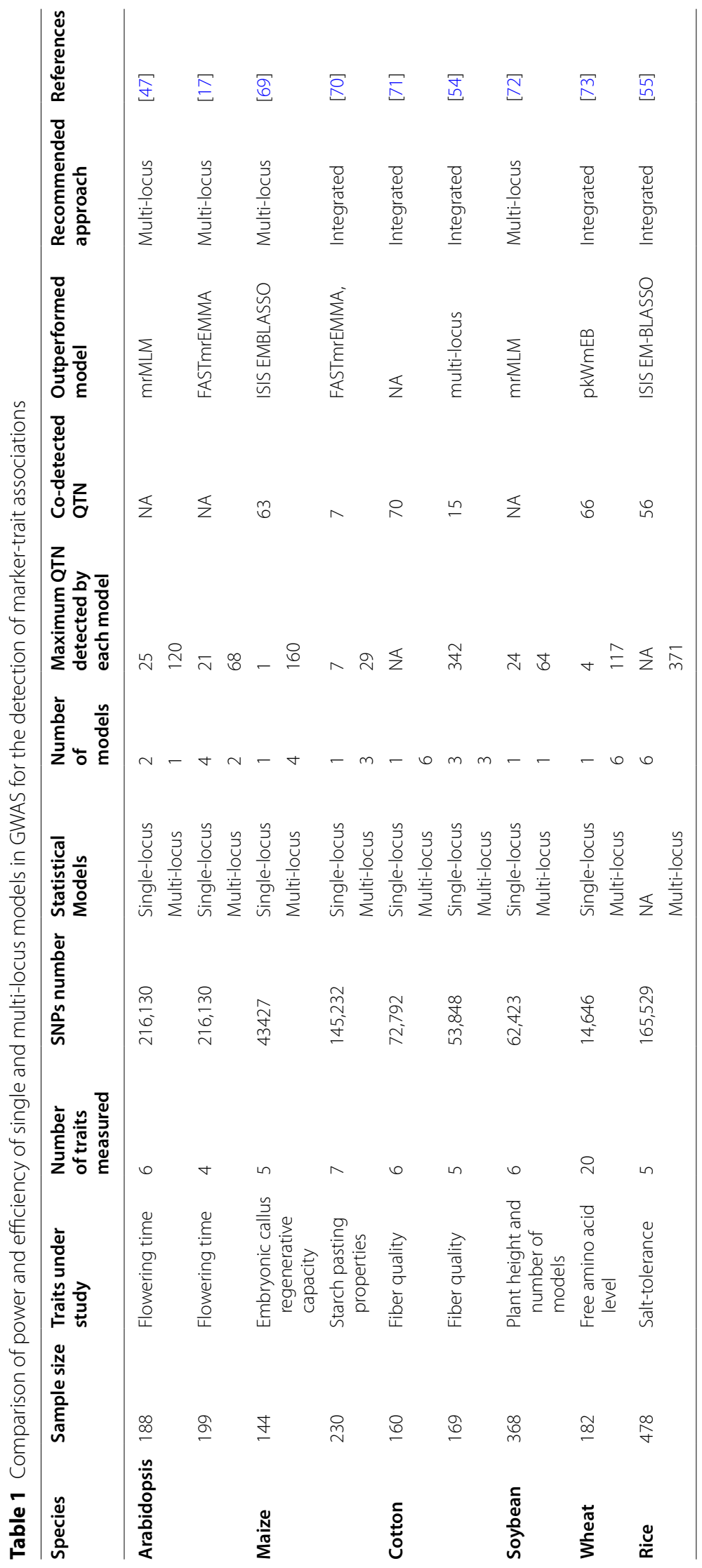


Table 2 Summary of pan genome assembly in various plant species

\begin{tabular}{|c|c|c|c|c|c|c|}
\hline \multirow[t]{2}{*}{ Plants } & \multirow{2}{*}{$\begin{array}{l}\text { Number of } \\
\text { assembled genome }\end{array}$} & \multirow[t]{2}{*}{ References genome } & \multicolumn{4}{|l|}{ Pan-genome } \\
\hline & & & $\begin{array}{l}\text { Number of total } \\
\text { genes }\end{array}$ & $\%$ core gene & $\begin{array}{l}\% \text { of dispensable } \\
\text { gene }\end{array}$ & References \\
\hline Brassica & 21 & Darmor-bzh & 105,672 & 56 & 42 & [80] \\
\hline Sesame & 5 & Zhongzhi13 & 26,472 & 58.21 & 41.79 & [94] \\
\hline \multirow[t]{2}{*}{ Maize } & 3 & B73 & 59,080 & 48.6 & 51.4 & [90] \\
\hline & 96 & B73 & $4,400,000$ & $74 \%$ & $26 \%$ & [30] \\
\hline Rice & 66 & Nipponbare & 42,580 & 61.94 & 30.06 & [89] \\
\hline Arabidopsis & 18 & TAIR10 & 37,789 & 69.8 & 30.2 & [95] \\
\hline Soybean & 7 & GmaxW82 & NA & 48.6 & 51.4 & [91] \\
\hline
\end{tabular}

NA data not available

of capsule per plant, seed coat color, seed size, seed oil content, seed yield, and branching habit have been reported in the cultivated sesame [11, 14, 104-107]. Besides the huge phenotypic variation harbored in sesame germplasm, various molecular marker-based high levels of genetic diversity were also documented within many landraces and cultivars collected from different areas around the world (Table 3) $[1,14,15,104,106$, 109, 110, 115-134]. Recently, advances in next-generation sequencing technologies have facilitated SNPbased genetic diversity analysis in sesame. Globally, high levels of genetic diversity in diverse sesame germplasm from Asia, Europe, America, and Africa were reported (Table 4) [14, 15, 36, 135, 136].

\section{Development of GWAS populations}

In China, there are over 8,000 accessions of sesame deposited in the National Mid-term Gene Bank of China located in the Oil Crops Research Institute of Chinese Academy of Agricultural Sciences (OCRI-CAAS) [14]. Similarly, about 4,500 sesame accessions conserved in the National Long-term Gene bank in Beijing [107] (Fig. 1). Based on these large collections, strategies to build a sesame core collection have started early in the year 2000 using morphological descriptors and later, molecular tools $[14,15,106,107,137]$. Ultimately, a sesame core collection encompassing 705 diverse accessions including 405 landraces, 95 cultivars from China, and 205 accessions from 28 other countries was established at OCRI

Table 3 Summary of molecular marker based genetic diversity and population structure analysis in sesame

\begin{tabular}{|c|c|c|c|c|c|c|c|c|c|}
\hline $\begin{array}{l}\text { Number of } \\
\text { accessions }\end{array}$ & $\begin{array}{l}\text { Source of } \\
\text { collection }\end{array}$ & Marker type & Marker size & $\begin{array}{l}\text { Detected } \\
\text { alleles }\end{array}$ & $\begin{array}{l}\text { Number of } \\
\text { allele per } \\
\text { locus }\end{array}$ & PIC & $\begin{array}{l}\text { Genetic } \\
\text { diversity }\end{array}$ & $\begin{array}{l}\text { Sub } \\
\text { populations } \\
\text { identified }\end{array}$ & References \\
\hline 96 & $\begin{array}{l}\text { Asia and Africa } \\
\text { ( } 22 \text { countries) }\end{array}$ & SSR & 33 & 137 & 4.15 & 0.45 & 0.508 & 5 & [108] \\
\hline 153 & $\begin{array}{c}\text { Worldwide (22 } \\
\text { countries) }\end{array}$ & SSR & 16 & 121 & 7.6 & 0.42 & 0.46 & 3 & [109] \\
\hline 404 & $\begin{array}{c}\text { Chinese core } \\
\text { collection }\end{array}$ & SRAP and SSR & 14 & 126 & 9 & 0.39 & 0.24 & 2 & [107] \\
\hline 453 & $\begin{array}{l}\text { Chinese core } \\
\text { collection }\end{array}$ & SRAD and SSR & 14 & 126 & 9 & 0.3467 & 0.2218 & 9 & [106] \\
\hline 49 & India & SSR & 20 & NA & 3 & 0.718 & NA & 2 & [110] \\
\hline 277 & 15 countries & SSR & 14 & 158 & 11.3 & 0.568 & NA & 4 & [111] \\
\hline 96 & China & SSR and InDels & 44 & 113 & 2.6 & 0.31 & 0.37 & 2 & [104] \\
\hline 545 & $\begin{array}{l}390 \text { from China, } \\
155 \text { outside } \\
\text { China }\end{array}$ & SSR & 42 & 106 & NA & 0.41 & 0.645 & 3 & {$[112]$} \\
\hline 216 & $\begin{array}{l}\text { Chinese core } \\
\text { collection }\end{array}$ & $\begin{array}{l}\text { SSR, SRAD and } \\
\text { AFLP }\end{array}$ & 79 & 338 & 2 & 0.25 & 0.2090 & 2 & [113] \\
\hline 216 & $\begin{array}{l}\text { Chinese core } \\
\text { collection }\end{array}$ & $\begin{array}{l}\text { SSR, SRAD and } \\
\text { AFLP }\end{array}$ & 79 & 608 & 2 & 0.16 & 0.13 & 2 & [114] \\
\hline 130 & China & SSR and InDels & 88 & 325 & 3.69 & 0.36 & 0.432 & 2 & [115] \\
\hline
\end{tabular}


Table 4 Summary of SNP marker based genetic diversity and population structure analysis in sesame

\begin{tabular}{|c|c|c|c|c|c|c|c|c|c|}
\hline $\begin{array}{l}\text { Number of } \\
\text { accessions }\end{array}$ & $\begin{array}{l}\text { Sources of } \\
\text { accessions }\end{array}$ & $\begin{array}{l}\text { Number of } \\
\text { effective } \\
\text { SNPs }\end{array}$ & $\begin{array}{l}\text { SNPs } \\
\text { detection } \\
\text { approach }\end{array}$ & $\begin{array}{l}\text { Average } \\
\text { marker } \\
\text { density/SNP }\end{array}$ & $\begin{array}{l}\text { Average } \\
\text { nucleotide } \\
\text { diversity of } \\
\text { the panel }\end{array}$ & $\begin{array}{l}\text { Genetic } \\
\text { distance }\end{array}$ & $\begin{array}{l}\text { Average } \\
\text { gene } \\
\text { diversity }\end{array}$ & $\begin{array}{l}\text { Number of } \\
\text { subgroups } \\
\text { identified }\end{array}$ & References \\
\hline 95 & $\begin{array}{l}\text { Mediter- } \\
\text { ranean } \\
\text { sesame core } \\
\text { collection } \\
\text { (21 geo- } \\
\text { graphical } \\
\text { regions) }\end{array}$ & 5,292 & ddRAD & $46 \mathrm{SNP} / \mathrm{kb}$ & NA & $\begin{array}{c}0.023 \text { to } \\
0.524\end{array}$ & 0.28 & & [119] \\
\hline 366 & HSRC-HAAS & 89,924 & SLAF-seq & $1 \mathrm{SNP} / 2.6 \mathrm{~kb}$ & $1.1 \times 10^{-3}$ & 0.01 to 0.42 & 0.17 & 3 & [122] \\
\hline 705 & $\begin{array}{l}\text { China gene } \\
\text { bank }\end{array}$ & 254,781 & $\begin{array}{l}\text { Whole- } \\
\text { genome } \\
\text { sequencing }\end{array}$ & $1 \mathrm{SNP} / 50 \mathrm{bp}$ & $2.4 \times 10^{-4}$ & 0.02 & & 2 & [15] \\
\hline 29 & $\begin{array}{l}\text { China gene } \\
\text { bank }\end{array}$ & 127,347 & $\begin{array}{l}\text { Whole- } \\
\text { genome } \\
\text { sequencing }\end{array}$ & NA & $1.5 \times 10^{-4}$ & NA & NA & NA & [14] \\
\hline
\end{tabular}

[15]. The entire panel was re-sequenced on Illumina HiSeq 2000 (http:/www.ncgr.ac.cn/ SesameHapMap), in which a total of $5,407,981$ SNPs were detected in the genome with an average of 2 SNP per $50 \mathrm{bp}$ (Fig. 2). This panel shows ideal characteristics for the implementation of GWAS, including high phenotypic variability, low population structure and genetic differentiation among groups, and a moderate decline in LD $(\sim 88 \mathrm{~kb})$ [15]. However, most of the accessions (70.1\%) included in this panel represent only one country while the other

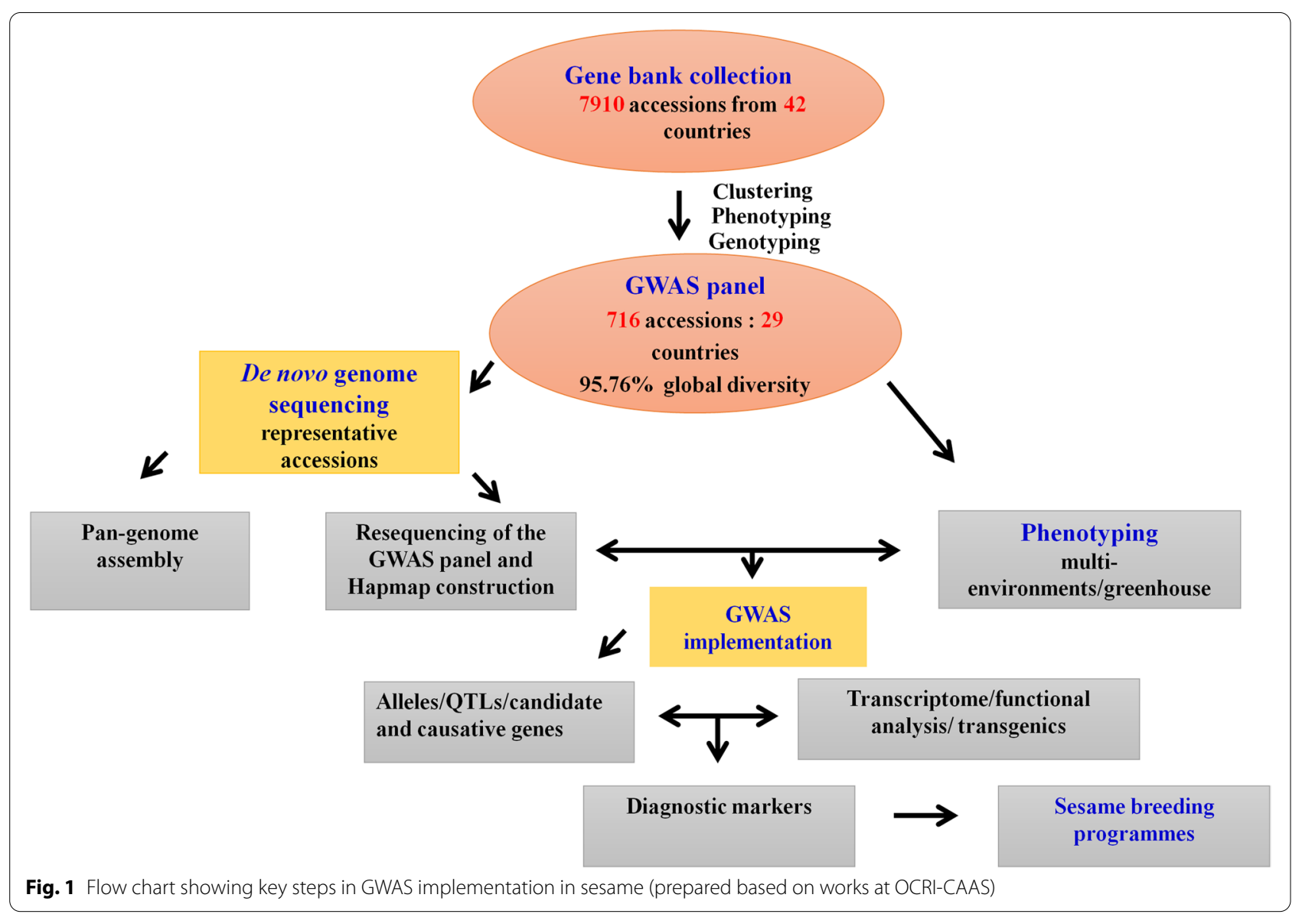




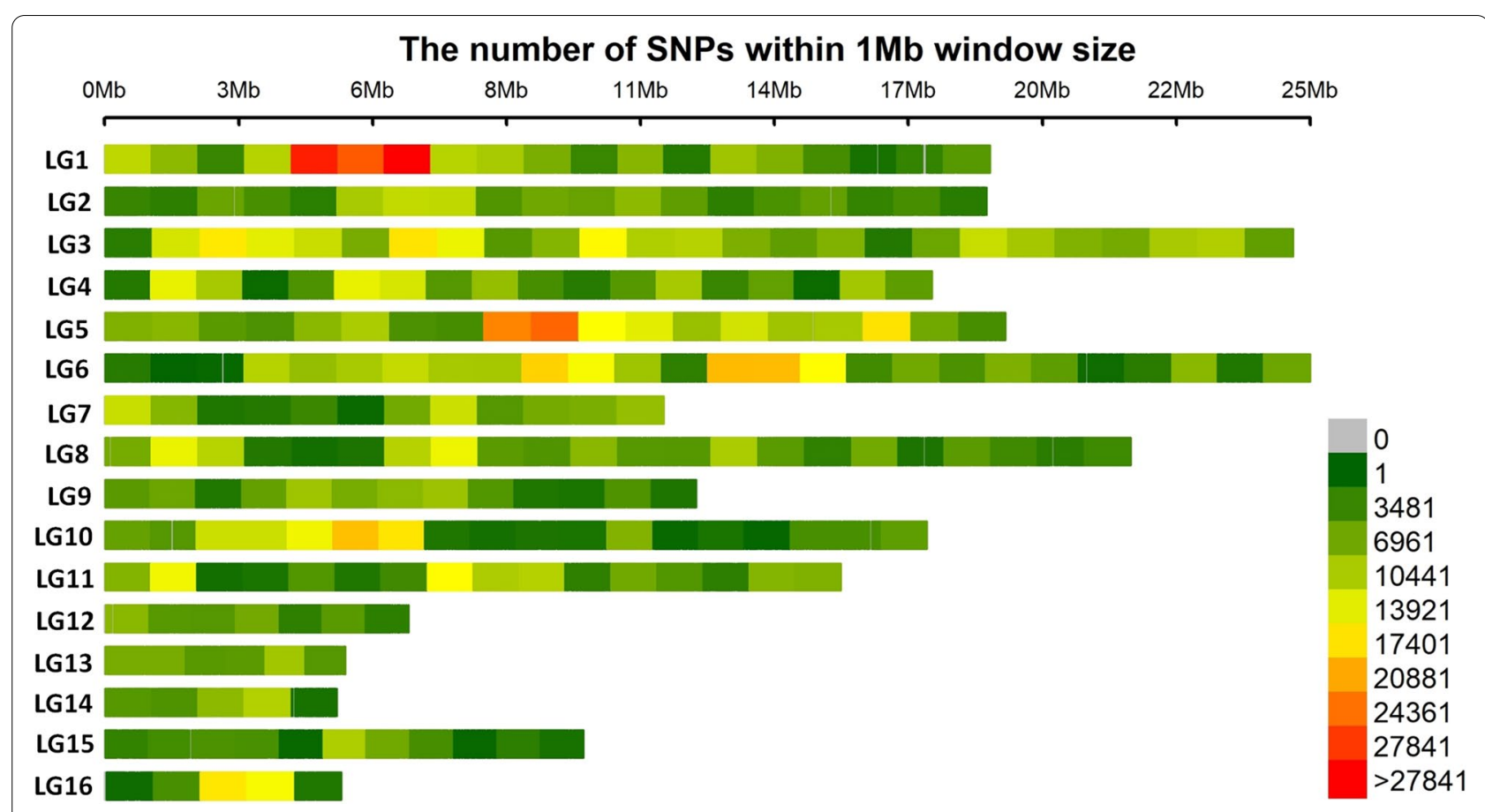

Fig. 2 Single-nucleotide polymorphism distributions on the 16 linkage groups (LGs) of the sesame genome assembly v1. The horizontal axis shows the LG length; the 0 27841 legend insert shows the SNP density

28 countries are represented only by $29.9 \%$ of the accessions. Furthermore, a limited number of African sesame $(\sim 3 \%)$ was included in this study, although Africa is the main source of diverse sesame landraces [108]. Therefore, for exploiting the genetic bases of important agronomic traits and detection of potential causative genes, there is a need to update this GWAS population panel by including more materials representing diverse agroecological origins across the world. Another associationmapping panel population was developed by the sesame research group in Henan Sesame Research Center, Henan Academy of Agricultural Sciences (HSRC-HAAS) [122, 136] consisting of 366 germplasm accessions representing about $89.9 \%$ from China and the rest $10.1 \%$ from 11 countries. This population also showed high phenotypic and genetic diversity, relatively good SNP density (1 SNP per $2.6 \mathrm{~kb}$ with $42,781 \mathrm{SNPs}$ in total) and moderate decay in LD ( 99 kb) [122]. However, this panel also has limited geographical representation. Further GWAS panel populations have been recently built from Korean core collections. However, the population size and SNP density were very low: 96 accessions and 5,962 SNPs [36]; 87 accessions and 8,883 SNPs [135]. Overall, to explore the genetic bases of economically important agronomic traits and identify possible causative genes, these developed GWAS panels need to be updated by providing more materials reflecting diverse agro-ecological backgrounds worldwide.

\section{Advantages and limitations for GWAS implementation in sesame \\ Advantages}

Implementation of GWAS based on high-quality genome sequences results generally in a more accurate prediction and mining of potential causative genes. The high-resolution positioning of SNPs in the genome along the entire chromosomes can unravel the genetic architecture of target traits; hence, GWAS can detect more significant associations, candidate genes, and genomic locations with high power and efficiency. Since 2014, the development of a high-quality draft genome of the sesame genotype 'Zhongzhi13' [14] has opened the door for genomic research in sesame. Sesame has a small diploid genome estimated at $350 \mathrm{Mb}$, of which $274 \mathrm{Mb}$ draft genome was assembled, and 27,148 protein-coding genes were predicted. Another genome sequence was also published during the same period from the modern cultivar 'Yuzhi1' [138]. Progresses in genome sequencing technologies associated with the reduction of sequencing costs have created opportunities for additional genome sequencing projects in sesame. The reference genome was updated to have a higher resolution [39] and the genome sequences of different sesame landraces including 'Baizhima' and 'Mishuozhima' [15] and a modern cultivar 'Swetha' [139] were also published. Furthermore, the assembly of a sesame pan-genome from five different genomes identified 15,890 dispensable genes, 
providing a rich resource for comprehensive gene discovery and superior allele mining through GWAS [94]. Similarly, the availability of tremendous transcriptome data from diverse sesame tissues, various growth conditions and from wild Sesamum species such as S. radiatum and S. mulayanum (Table 5) (https://www.ncbi. nlm.nih.gov/bioproject/?term $=($ (sesame $) \% 20$ AND\% $20 \% 22$ Sesamum\%20indicum\%22[orgn:_txid4182])\% 20AND\%20bioproject_sra[filter]\%20NOT\%20bioproje ct_gap[filter]) facilitates post-GWAS works particularly for pinpointing candidate genes and their functional analysis. The availability of several mapping populations [11] is also very useful for validating or polishing GWAS findings. Besides, the availability of functional genomic databases such as Sinbase (http://ocri-genomics.org/ Sinbase/index.html), SesameFG (http://sesame-bioinfo. org/SesameFG/) and Sesame HapMap that have been deployed to facilitate genome excavation, comparative genomics, gene expression analysis, are highly useful for post-GWAS investigations $[15,105,140]$.

To further facilitate the exploitation of GWAS results as well as all genetic discoveries available in sesame, we have developed a novel database named Sesamum indicum Genetic Discovery Database (SiGeDiD) (http:// sigedid.ucad.sn/). SiGeDiD is a flexible online catalog of all genetic and genomic discoveries including, candidate genes, QTLs and functional molecular markers in sesame (Fig. 3). It is an essential platform for comparative analysis of GWAS projects in sesame and facilitates gene discovery, particularly the identification of pleiotropic genomic regions/genes that have been identified from different GWAS and other genetic/genomic studies.
The website is user-friendly and we integrated a module allowing researchers to upload directly their findings in SiGeDiD. Currently, the BLAST functionality is unavailable but $\mathrm{SiGeDiD}$ will be updated to make it more interactive and fully functional.

Collectively, the availability of enormous genomic resources, the small genome size of sesame, comprehensive GWAS panels, diverse mapping populations, high genetic diversity, low population structure, and relatively low LD are advantageous for GWAS implementation in sesame.

\section{Limitations}

While GWAS provides an opportunity to investigate a range of novel genes associated with important agronomic traits, this method does not necessarily identify causal variants and genes [141]. When GWAS is completed, it is often necessary to take additional steps to investigate the functional and causal variants and their target genes in which transgenic experiments may ultimately be implemented. Sesame, however, is a recalcitrant plant for genetic transformation, so there are limited validations of GWAS-identified SNPs using a transgenic approach. Besides, although the LD decay rate in sesame is relatively lower than that of other selfpollinating crops, including rice $(\sim 100-350 \mathrm{~kb})[142,143]$, soybean $(\sim 574 \mathrm{~kb})[144,145]$ and brassica $(\sim 405 \mathrm{~kb})$ [146], it showed a higher LD decay rate than other crosspollinating species, including maize $(\sim 5.39-15.53 \mathrm{~kb})$ [147]. Consequently, the modest level of LD decay rate $(88 \mathrm{~kb})$ reported in sesame suggests that GWAS resolution may not easily resolve to the causative gene unless

Table 5 Summary of RNA-seq data available for various investigated tissues in sesame

\begin{tabular}{llll}
\hline Tissue sample & Condition/topic & Sample size & SRA accession numbers \\
\hline Root & Salt & 30 & PRJNA524278 \\
Root & Osmotic stress & 12 & PRJNA552167 \\
Seed and capsule & Seed and carpel development & 22 & SRR6010084- \\
& & SRR6010093- & SRX396185-SRX396196 \\
& Drought & 30 & SRP095661 \\
Root & Growth habit & KU240042 \\
Root, leaf, stem and shoot apical & Fertile and sterile flower buds & SRP095661 \\
Flower buds & Waterlogging & 2 & SRR2886790 \\
Root & Fusarium wilt disease & 6 & \\
Leaf & Multiple tissues & 8 & SRA122023 \\
Leaf, root, stem and flower & Seed developmental stage & & SRP034617 \\
Seed & Fusarium wilt disease & 12 & SRA047567.1 \\
Seedling & Growth and development & & SRA047563.1 \\
Seedling & Oil content & 24 & JK045130-JK086377 \\
Seed & Multiple tissues & 6 & SRP006700 \\
Root, leaf, flower, developing seed, and shoot & & \\
tip & & 5 & \\
\hline
\end{tabular}




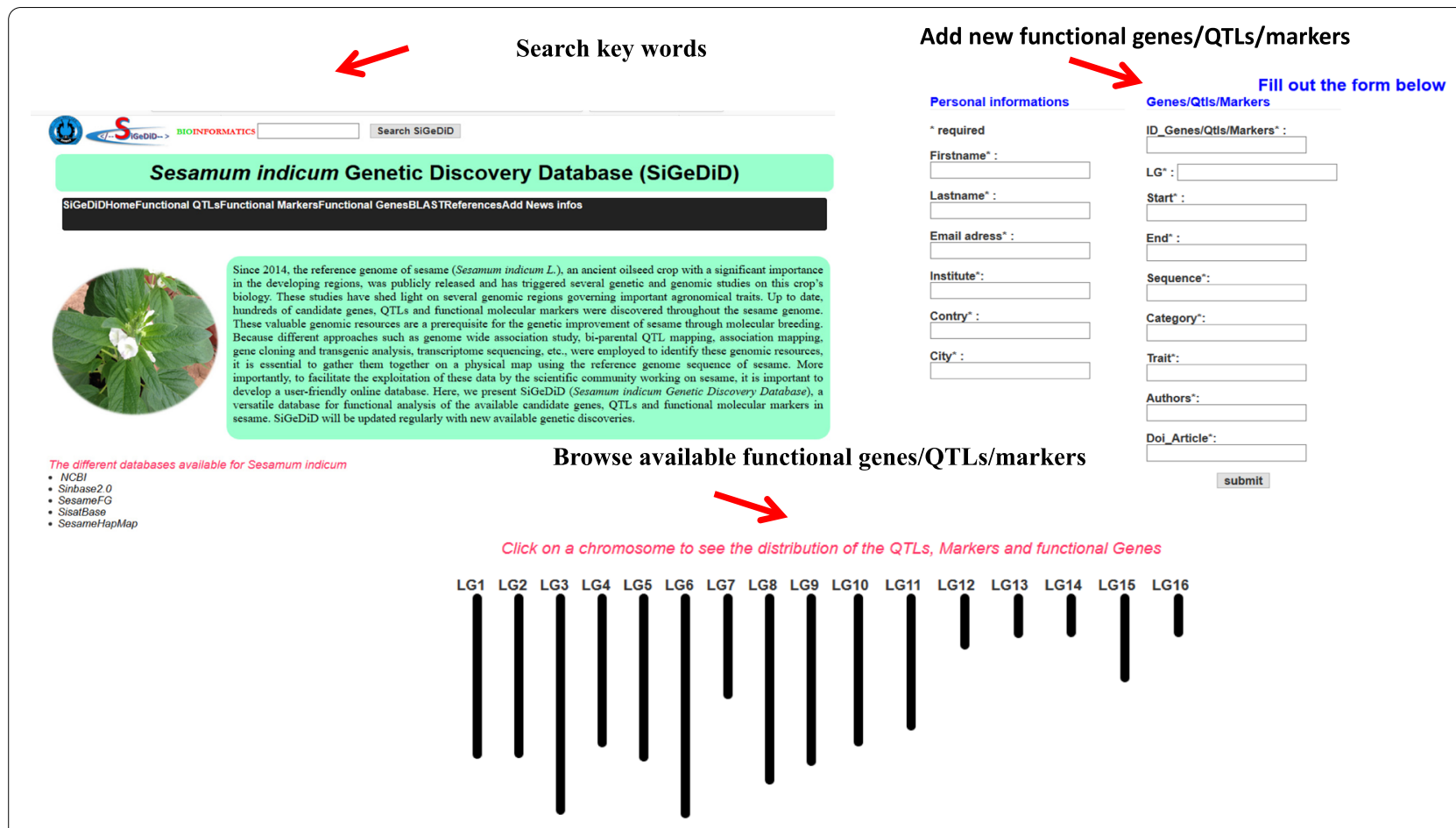

Fig. 3 SiGeDiD: an online catalogue of functional genomic discoveries in sesame (http://sigedid.ucad.sn/)

a high marker density is used. GWAS, therefore, could have a limited efficiency on trait-based QTL regions or causative genes detection in the absence of high marker density. Another limitation of GWAS in sesame is that many sesame cultivars are highly photosensitive, so field phenotyping and collecting reliable data in various regions of the world is difficult.

\section{GWAS applications in sesame}

From 2015, several GWAS projects have been successfully implemented in sesame to uncover the genetic bases of key agronomic traits such as oil content, oil nutrient composition, seed yield, and yield-related components, seed coat color, morphological characteristics, disease resistance salt tolerance, waterlogging resistance, drought tolerance, root traits and nutritional values [15, 33-36, 135, 136, 148]. As to our knowledge, all GWAS projects conducted so far in sesame were based on a single-locus method (EMMA) and the majority was implemented on the GWAS panel developed at OCRI-CAAS. In this work, we summarize all of the results of GWAS reported by different groups of sesame researchers (Table 6 and Fig. 4). A large scale GWAS was conducted by investigating the natural variation of 705 sesame accessions based on 169 sets of phenotypic data including, oil content, nutrient composition, yield components, morphological characteristics, growth cycle, coloration and disease resistance. In total, $1,805,413$ SNPs were used. This has led to the identification of 446 significantly associated SNPs with the phenotypic variation. Following in-depth analyses of the major loci, a total of 46 causative genes including genes related to flower lip color (SiGL3), petiole color (SiMYB113 and SiMYB23), oil content (SiPPO), fatty acid biosynthesis (CXE17 and GDSL-like lipase) and yield (SiACS) were identified [15]. Similarly, GWAS of 39 yield-related traits was also conducted [34] using the same population as the previous study [15]. In total, 646 loci associated with traits of interest and 48 potential genes significantly associated with the functional loci were identified. They reported several candidate homologs genes involved in seed formation and some novel candidate genes (SiLPT3 and SiACS8) which may control capsule length and capsule number [34]. Likewise, variations in PEG-induced drought stress and salt stress tolerance were investigated in 490 diverse sesame accessions (representing 33 countries in Asia, Africa, America and Europe) based on GWAS [33]. A total of 132 significant SNPs resolved to nine QTLs and 151 total genes of which SiEMF1, SiGRV2, SiCYP76C7, SiGRF5, SiCCD8, SiGPAT3, SiGDH2, SiRABA1D were detected as potential genes regulating drought stress while for salt tolerance, a total of 120 significant SNPs resolved to 15 QTLs and 241 genes of which of 
Table 6 Summary for GWAS results reported so far in sesame

\begin{tabular}{|c|c|c|c|c|c|c|c|c|}
\hline Sample size & $\begin{array}{l}\text { Targeted } \\
\text { traits }\end{array}$ & Group of traits & SNP size & SNP density & $\begin{array}{l}\text { Significant } \\
\text { associations } \\
\text { identified }\end{array}$ & $\begin{array}{l}\text { Number of } \\
\text { candidate } \\
\text { genes }\end{array}$ & Potential genes & References \\
\hline 705 & 56 & $\begin{array}{l}\text { Oil content, nutrient } \\
\text { composition, yield } \\
\text { components, } \\
\text { morphological } \\
\text { characteristics, } \\
\text { growth cycle, col- } \\
\text { oration and disease } \\
\text { resistance }\end{array}$ & $1,805,413$ & 1SNP/50bp & 446 & 46 & $\begin{array}{l}\text { - SiGL3 flower in lip } \\
\text { colour } \\
\text { - SiMYB113 \& SiMYB23 } \\
\sim \text { petiole colour } \\
\text { - SiPPO oil content, } \\
\text { seed coat color, } \\
\text { protein content } \\
\text { - SIN_1016759 } \\
\text { encodes a pre- } \\
\text { dicted PPO seed } \\
\text { coat color } \\
\text { - CXE17\& GDSL-like } \\
\text { lipases encoding } \\
\text { lipase } \\
\text { - SIN_1019167 \& } \\
\text { SIN_1009923 } \\
\text { 〜encoding lipid } \\
\text { transfer protein } \\
\text { - SiACNA, SiDGAT2, } \\
\text { SiFATA, SiFATB and } \\
\text { SiSAD fatty acid } \\
\text { composition } \\
\text { - SiFAD2 oleic acid } \\
\text { desaturase } \\
\text { - SiACS seed yield }\end{array}$ & [15] \\
\hline 705 & 39 & $\begin{array}{l}\text { Yield index, seed } \\
\text { traits, capsule } \\
\text { number, capsule } \\
\text { size, and capsule } \\
\text { pericarp }\end{array}$ & $1,805,413$ & $1 \mathrm{SNP} / 50 \mathrm{bp}$ & 646 & 48 & $\begin{array}{l}\text { - SiACS8 capsule } \\
\text { number } \\
\text { - SiLPT3 capsule } \\
\text { length }\end{array}$ & [34] \\
\hline 490 & 4 & $\begin{array}{l}\text { Drought and salt } \\
\text { tolerances }\end{array}$ & $1,005,413$ & $2,7 \mathrm{SNP} / \mathrm{kb}$ & 252 & 40 & $\begin{array}{l}\text { - SiOPR3 increase of } \\
\text { abscisic acid during } \\
\text { desiccation } \\
\text { - SiWRKY69 func- } \\
\text { tioning in response } \\
\text { to dehydration } \\
\text { stress } \\
\text { - SiCCD8 functions } \\
\text { as a carotenoid } \\
\text { cleavage dioxyge- } \\
\text { nase } \\
\text { - SiMLP31 salicylic } \\
\text { acid synthesis } \\
\text {-SiANTH phospha- } \\
\text { tidic acid-binding } \\
\text { protein } \\
\text {-SiHKT1 sodium } \\
\text { transporter } \\
\text {-SIN_1021330, } \\
\text { SIN_1021327, } \\
\text { SIN_1021326, } \\
\text { SIN_1021325, } \\
\text { SIN_1021324, } \\
\text { SIN_1021323 and } \\
\text { SIN_1021322 } \\
\text { encoding sesame } \\
\text { peroxidase }\end{array}$ & [33] \\
\hline
\end{tabular}


Table 6 (continued)

\begin{tabular}{|c|c|c|c|c|c|c|c|c|}
\hline Sample size & $\begin{array}{l}\text { Targeted } \\
\text { traits }\end{array}$ & Group of traits & SNP size & SNP density & $\begin{array}{l}\text { Significant } \\
\text { associations } \\
\text { identified }\end{array}$ & $\begin{array}{l}\text { Number of } \\
\text { candidate } \\
\text { genes }\end{array}$ & Potential genes & References \\
\hline 400 & 5 & $\begin{array}{l}\text { Drought (stem } \\
\text { length, survival } \\
\text { rate, wilting level, } \\
\text { capsule number } \\
\text { and seed yield) }\end{array}$ & $1,000,939$ & $5 \mathrm{SNP} / \mathrm{kb}$ & 569 & 102 & $\begin{array}{l}\text { - SiABI4 involved in } \\
\text { abscisic acid signal } \\
\text { transduction } \\
\text { - SiTTM3, SiGOLS1, } \\
\text { SiPOD3 \& SiNIMIN1 } \\
\sim \text { involved in } \\
\text { drought tolerance } \\
\text { - SiSAM modulates } \\
\text { polyamine levels }\end{array}$ & [35] \\
\hline 96 & 1 & Vitamin E & 5,962 & 2.3SNP /100 kb & 8 & 12 & $\begin{array}{l}\text { - LG08_6621957 loci } \\
\sim \gamma \text {-tocopherol } \\
\text {-SLG03_13104062 } \\
\text { loci } \sim \beta \text {-tocotrienol }\end{array}$ & {$[36]$} \\
\hline 87 & 1 & $\begin{array}{l}\text { Phytophthora } \\
\text { disease-resistant }\end{array}$ & 8,883 & NA & 44 & 68 & $\begin{array}{l}\text {-SIN_1019026\& } \\
\text { SIN_1019021 regu- } \\
\text { lation of pathogen- } \\
\text { induced signaling } \\
\text {-SIN_1019014\& } \\
\text { SIN_1018999 } \\
\text { encoded F-box } \\
\text {-SIN_1019019\& } \\
\text { SIN_1018986 } \\
\text { cytochrome P450 } \\
\text { family protein } \\
\text { - SIN_1019026 \& } \\
\text { SIN_1019021 } \\
\text { encoding ubiq- } \\
\text { uitin ligases and } \\
\text { ubiquitin-related } \\
\text { modifiers }\end{array}$ & [135] \\
\hline 366 & 1 & Seed coat color & 42,781 & 1SNP/2.6kb & 224 & 92 & $\begin{array}{l}\text { - SIN_1016759 PPO } \\
\text { - SIN_1023237 } \\
\text { laccase3 } \\
\text { - SIN_1006022 } \\
\text { cytochrome P450 } \\
\text { - SIN_1023226 \& } \\
\text { SIN_1024895 } \\
\text { WRKY and bHLH130 }\end{array}$ & [136] \\
\hline 327 & 7 & Root traits & $1,000,000$ & $5 S N P / k b$ & 409 & 32 & $-\operatorname{SiBRB}$ & [148] \\
\hline
\end{tabular}

SiLHCB6, SiMLP31, SiPOD, SiHSFA1, SiDUF538, SiCC-NBS-LRR, SiUDG, SiGPAT3, SiNAC43, SiGDH2, SiCP24, SiWRKY14, SiXXT5, SiXTH15, and SiG6PD1 were detected as potential genes [33]. Later on, GWAS was conducted to investigate genetic variants governing drought tolerance in 400 sesame accessions [35]. A total of 140 reliable and stable QTLs were identified and resolved to 10 QTLs. Similarly, 120 genes, of which SiABI4, SiTTM3, SiGOLS1, SiNIMIN1, and SiSAM having high potentials to modulate drought tolerance in sesame, were identified [35]. Their study was the first to validate the function of a candidate gene from GWAS using transgenic approach. They demonstrated that sesame accessions originated from drought-prone agroecological regions have fixed several drought-tolerant alleles, though alleles contributing to high yielding under drought conditions are far from being fixed. Hence, sesame is mostly considered as a resilient crop because of the long-term adaptation to drought-prone agro-ecological regions. Additional new GWAS results were also reported recently [36, 135, 136] (Table 6). Based on genotyping by sequencing (GBS) method, [36] conducted GWAS on vitamin E and identified eight strongly linked SNPs and 12 genes with various regulatory functions, including transcription regulator $\mathrm{HTH}$, zinc ion binding protein, glycosylphosphatidylinositol (GPI)-anchor biosynthesis and ribosome protein. They also identified, two loci, LG_03_13104062 containing seven genes (SIN_1022039-SIN_1022045) and LG_08_6621957 containing five genes 


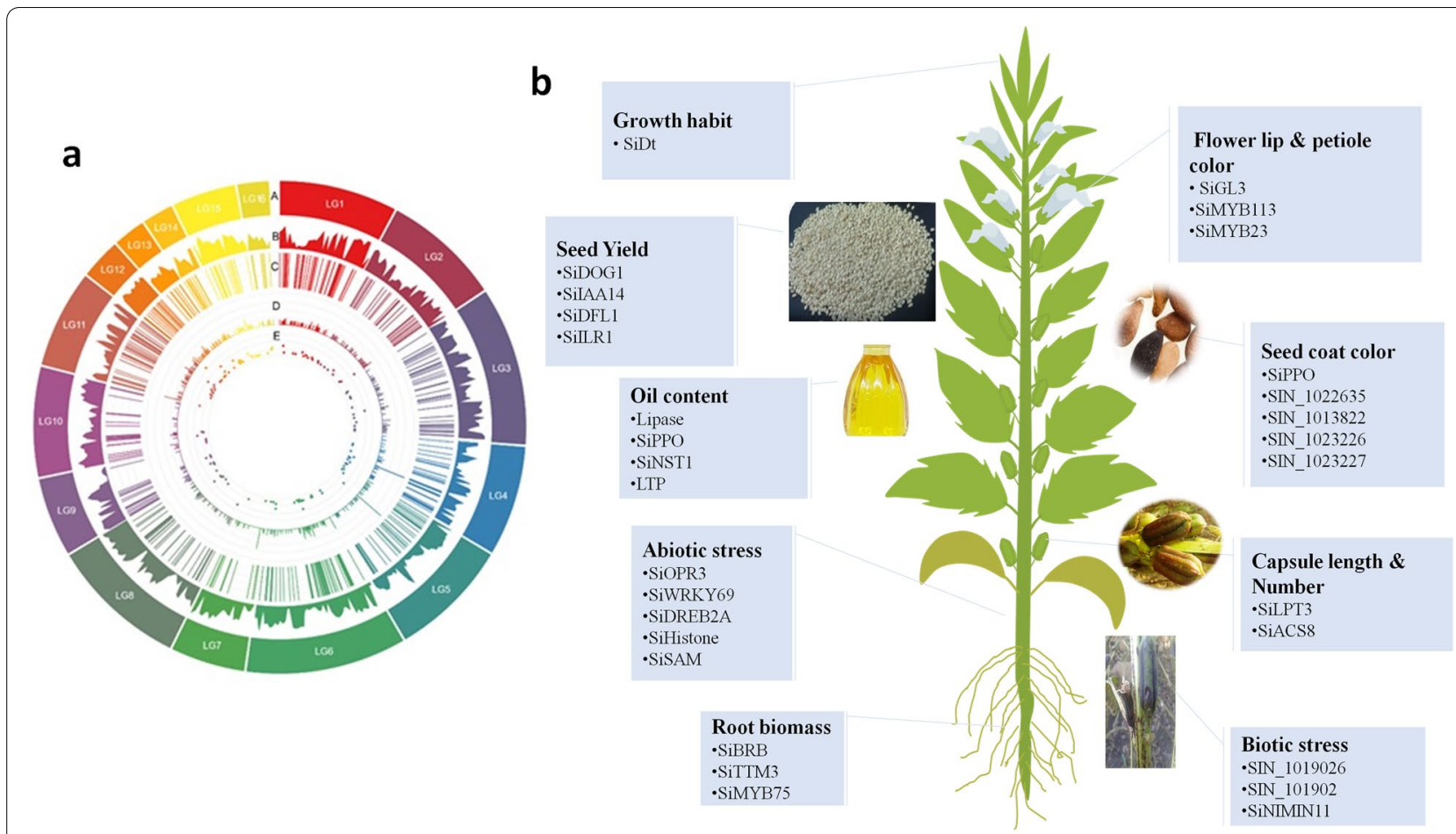

Fig. 4 GWAS applications in sesame. a Circos plot summarizing genetic findings of important agronomic traits in sesame. (A) Pseudomolecules (LG), (B) gene density, (C) QTL position, (D) -log(p) of the peak SNPS, (E) pleiotropic QTLs; b Schematic diagram showing potential candidate genes discovered so far related to important agronomic traits in sesame. The image of the sesame plant has been specifically designed in this study

(SIN_1001936-SIN_1001940), detected simultaneously on LGs 3 and 8, respectively, by employing two different models (GLM and MLM). Hence, the authors suggested that these two simultaneously detected loci have high potentials to control vitamin $\mathrm{E}$ in sesame. However, due to the limited numbers of SNPs $(5,962)$ and small panel size used in this GWAS, potential loci for this important trait may have been missed [136]. used genotype data from 42,781 SNPs and seed coat color trait from an association-mapping panel consisting of 366 sesame germplasms to identify 224 significantly associated SNPs. Based on the four most stable peaks/SNPs significantly associated with sesame seed coat color, they retained 92 candidate genes. Of these genes, SIN_1016759 (encoding predicted PPO) was also reported in previous GWAS by [15] and QTL mapping study by [39]. Using a mapping association of 87 sesame accessions and 8,883 SNPs, a GWAS on phytophthora blight resistance was conducted [135]. The result of this study suggested that SIN_1019016 was one of the candidate genes identified closely associated with phytophthora blight resistance in sesame. The limited SNP numbers called from the GBS approach and relatively small size of sesame accessions used in this study could have affected the GWAS output associated with trait under investigation. More recently, a comprehensive GWAS conducted by Dossa et al. [148] unraveled the genetic basis of seven root related traits. They reported 409 significant signals, 19 QTLs containing 32 candidate genes associated with sesame root traits. More importantly, they discovered an orphan gene named 'Big Root Biomass' (SIN_1025576) which modulates sesame root biomass through the auxin pathway [148]. In addition to the published GWAS findings, the OCRI-CAAS sesame research group has also several unpublished GWAS outputs on various agronomic traits including, waterlogging, chlorophyll, salt stress at the seedling stage and interestingly a metabolite based GWAS has been completed. These results will illuminate the genetic basis of important metabolites such as sesamin/sesamolin variation in sesame. All candidate genes, QTLs and SNPs will be regularly loaded into SiGeDiD (http:/sigedid.ucad.sn/) for further uses in sesame breeding projects.

\section{Potential of new statistical models to improve the accuracy and power of GWAS in sesame}

To our knowledge, multi-locus models have not yet been employed in sesame GWAS research and no previous study has compared different GWAS models (single 
locus and multi-locus models) in sesame. Herein, we tested the applications of new GWAS models in sesame based on quantitative (root length) and qualitative (seed coat color) traits. Natural variation in root length of 350 sesame accessions was collected from a field experiment following the methodology developed by Su et al. [149], and the genotypic data were obtained from 1,000,000 common SNPs. For the seed coat color GWAS, the 600 sesame accessions, and 1,000,000 common SNPs were used [15]. To investigate the phenotypic natural variation for the seed coat color, matured seeds from five capsules per genotype were collected and photographed with a high-resolution digital camera and the seed -coat color data, which was based on the red, green, and blue (RGB) values, were recorded following the methodological approach adopted by Zhang et al. [150]. Subsequently, three separate GWAS models, including two multi-locus models (mrMLM FASTmrEMMA and mrMLM ) and one single locus model (EMMAX) were selected (mainly because they do not require extensive phenotypic and genotypic data formatting) and were implemented using the phenotypic and genotypic data. We further compared the results of these three models to evaluate their potentials to reveal higher number of marker-trait associations and discover more candidate genes.

Our GWAS results for the two traits showed that a total of 190, 181 and 162 significant SNPs $(-\log 10(\mathrm{p})>$ 6) associated with root length were detected by FASTmrEMMA, mrMLM and EMMAX, respectively. Similarly, 67, 492 and 143 significant SNPs associated with seed coat color were detected by FASTmrEMMA, mrMLM and EMMAX, respectively (Fig. 5a-f; Table 7; Table S1). Of the significant SNPs associated with root length, 163 SNPs were identified simultaneously by all three models; all the SNPs identified by EMMAX were also identified simultaneously by both multi-locus models, while 18 SNPs were simultaneously and only detected by FASTmrEMMA and mrMLM (Fig. 5g). For the seed coat color associated SNPs, 67 and 27 SNPs were detected by all the three models and by two models (mrMLM and EMMAX), respectively (Fig. 5h). By considering all SNPs co-clustered with peak SNPs within a window

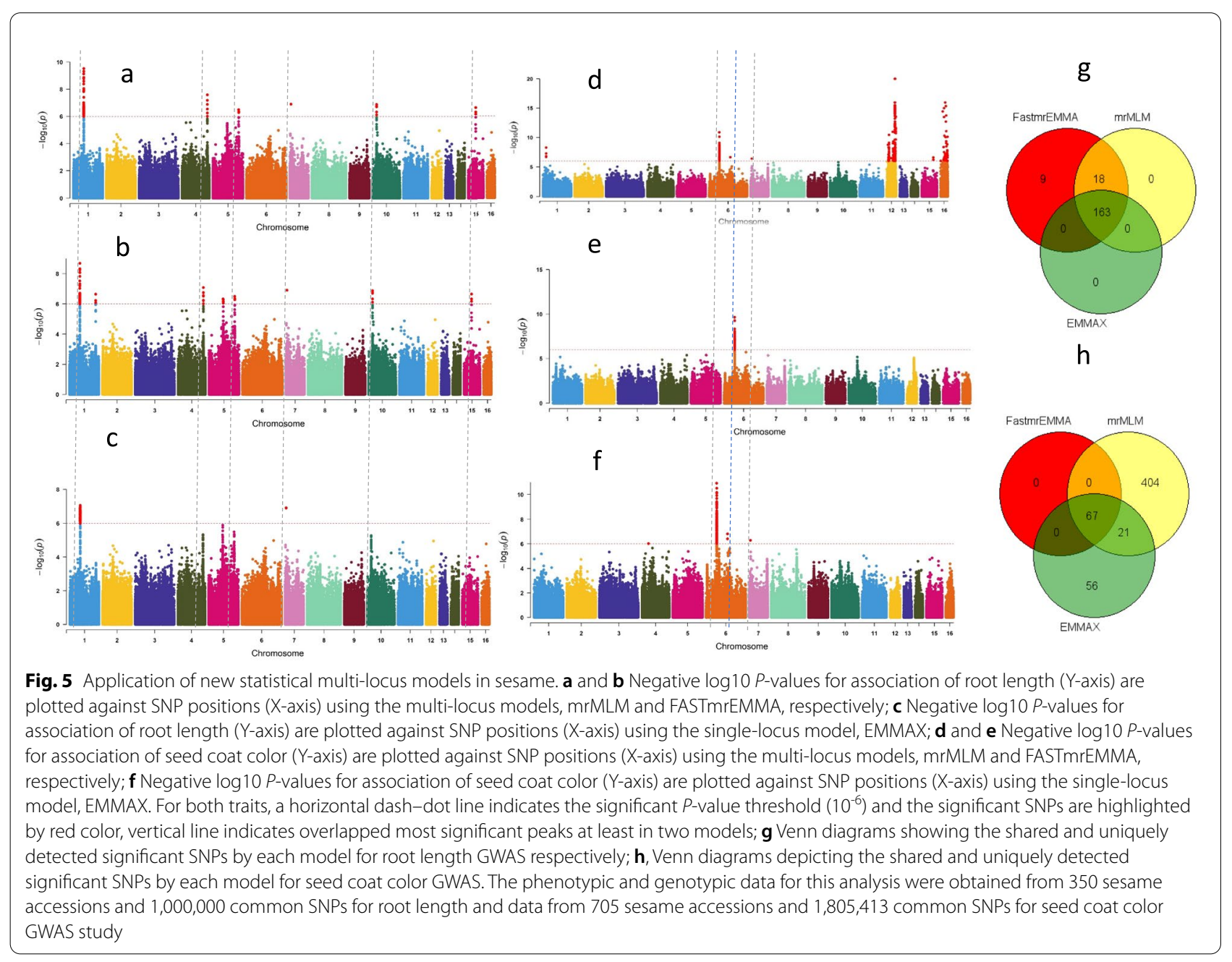


Table 7 Summary of significant SNPs associated with root length and seed coat color within the linkage groups (LG) identified by each model during GWAS in sesame

\begin{tabular}{|c|c|c|c|c|}
\hline \multirow[t]{2}{*}{ Trait } & \multirow[t]{2}{*}{ LG } & \multicolumn{3}{|l|}{ GWAS models } \\
\hline & & $\begin{array}{l}\text { mrMLM } \\
\text { FASTmrEMMA }\end{array}$ & mrMLM & Emmax \\
\hline \multirow[t]{7}{*}{ Root length } & LG1 & 167 & 163 & 162 \\
\hline & LG4 & 7 & 6 & 0 \\
\hline & LG5 & 7 & 3 & 0 \\
\hline & LG7 & 1 & 1 & 1 \\
\hline & LG10 & 5 & 5 & 0 \\
\hline & LG15 & 3 & 3 & 0 \\
\hline & Total & 190 & 181 & 163 \\
\hline \multirow[t]{7}{*}{ Seed coat color } & LG1 & 0 & 4 & 0 \\
\hline & LG4 & 0 & 0 & 0 \\
\hline & LG6 & 67 & 89 & 142 \\
\hline & LG7 & 0 & 1 & 1 \\
\hline & LG12 & 0 & 349 & 0 \\
\hline & LG16 & 0 & 48 & 0 \\
\hline & Total & 67 & 491 & 143 \\
\hline
\end{tabular}

of $200 \mathrm{~kb}$ as QTLs [35], a total of 19 and 34 QTLs were detected for root length and seed coat color, respectively, by all the three models (Table S1). Within these QTLs, we retrieved 26 and 47 genes for root length and seed coat color, respectively. Based on the robust QTLs codetected by different models identified for root length, nine potential candidate genes, including SIN_1017810, SIN_101781, SIN_1017812, SIN_1017815, SIN_1017843, SIN_1007064, SIN_1007065, SIN_1020072 and SIN_1017818 are proposed for further functional studies to pinpoint the causative gene (s). Regarding the seed coat color, the potential candidate genes identified in our study include SIN_1007188, SIN_1007221, SIN_1023226, SIN_1023227 and SIN_1023228. Interestingly, three genes detected in this study were previously reported by Mei et al. [136].

Collectively, the analysis of different GWAS models indicates the potential of using an integrated approach (single and multi-locus models) to improve the capacity and power of GWAS in sesame. This will help to detect more and novel marker-trait associations and candidate genes, particularly when investigating quantitative traits. It is also important to note that significantly associated regions simultaneously detected by more models in GWAS are more likely to be highly associated with the traits under investigation as compared with regions detected only by a single model. Hence, developing diagnostic markers for the co-detected associated regions could speed up sesame molecular breeding programmes.

\section{Conclusions}

Over the last five years, GWAS have been successfully implemented in sesame and is illuminating the genetic basis of many important agronomic traits. Even though a list of QTLs ( 300) and candidate genes ( 250) have been identified for qualitative and quantitative traits, more traits, including chlorophyll-yield, metabolite-GWAS, waterlogging, heat tolerance are under investigation. We envision that all these results will lead to the development of allele-specific diagnostic markers to be used as daily molecular tools in sesame breeding programmes. Though a high-quality sesame reference genome sequence has been developed, more often, there are limitations to find any candidate gene around the peak SNPs from GWAS. To overcome these limitations, we need to use the recently developed sesame pan-genome [94] for future GWAS implementations. The diversity of recently available sesame GWAS panels should be improved by integrating more accessions and wild species from different agro-ecological origins mainly from Africa. For this, an international collaboration between sesame researchers is highly required. Furthermore, collaboration between researchers for generating comprehensive germplasm characterization data using precise phenotyping platforms and in contrasting environments will permit more accurate dissection of the genetic architecture of complex traits in sesame. Efforts towards sharing genetic materials between research institutes are crucial for accelerating gene discovery. For example, the re-sequencing data of the 705 fully sequenced GWAS panel generated by OCRI is publicly available and if the germplasm, at least partly, could be shared with partners, more GWAS projects could be implemented on sesame, particularly on traits highly affected by environments. Similarly, working to develop an SNP chip can be an alternative for quick, lowcost, and easy genotyping of novel sesame collections to be used for future GWAS projects.

The application of new multi-locus GWAS models and integration of single- and multi-locus models will provide more efficiency and power in future GWAS implementation in sesame. Up to date, very few studies have validated the numerous GWAS findings in sesame. Therefore, follow-up studies are needed for further validating the favorable alleles identified from GWAS in independent populations and using other approaches (classical bi-parental QTL mapping, QTLseq, etc.). Validation of GWAS findings using transgenic approach is also instrumental in several plant species. In sesame, genetic transformation protocols using tissue culture techniques have been reported [151]. More studies on this topic are needed in order to develop a more effective genetic transformation protocol in sesame, for example using the flower dip technique [152]. Hairy 
root genetic transformation is also a flexible and rapid technique widely adopted in several recalcitrant plants to study gene functions [153]. We propose to develop a hairy root genetic transformation protocol in sesame combined with new genome editing technologies to confirm some important GWAS findings. Finally, projects aiming at developing diagnostic molecular markers based on GWAS peak SNPs and their favorable alleles should be instigated. This will considerably accelerate sesame molecular breeding.

\section{Abbreviations}

GWAS: Genome wide association study; LD: Linkage disequilibrium; QTL: Quantitative trait locus; QTN: Quantitative trait nucleotides; SiGeDiD: Sesamum indicum genetic discovery database; SNP: Single nucleotide polymorphism.

\section{Supplementary Information}

The online version contains supplementary material available at https://doi. org/10.1186/s12870-021-03046-x.

Additional file 1 : Table S1. Summary list of total QTLS and candidate genes identified in GWAS for root length and seed coat color along the linkage groups in sesame by multi-locus and single-locus models. Table S2. Summary of QTL and candidate genes detected by each GWAS model. Table S3. Candidate genes detected in each LG for each model.

\section{Acknowledgements}

Data summarized in this paper have been generated through works of several authors which we would like to thank for their continuous efforts for the emergence of sesame crop. We are also thankful to Dr Muhammad Amjad Nawaz for his assistance in drawing the sesame plant.

\section{Authors' contributions}

$M B, K D$ and $L W$ conceived and designed the paper; $M B, K D, L W, J Y, D D, X$ $Z$ collected and analyzed the literature; K D and M B conducted multi-locus GWAS analyses; P A M, I N D, K D and D D designed and developed SiGeDiD; $M B$ and $K D$ drafted the paper and prepared the figures; $L W, J Y, D D, X Z$ have revised the manuscript. All authors have read and approved the final version of the manuscript.

\section{Funding}

The study was supported by Wuhan cutting-edge application technology fund (2018020401011303), the Science and Technology Innovation Project of Hubei province (201620000001048), the Natural Science Foundation of Hubei Province, China (2019CFB574), the Fundamental Research Funds for Central Non-profit Scientific Institution (1610172019004, Y2019XK15-02), the Agricultural Science and Technology Innovation Project of the Chinese Academy of Agricultural Sciences (CAAS-ASTIP-2013-OCRI) and the China Agriculture Research System (CARS-14). The funders have no role in the design of the study and collection, analysis, and interpretation of data and in writing the manuscript.

\section{Availability of data and materials}

The data used in this review article are available in the supplementary files and within the manuscript.

\section{Declarations}

Ethics approval and consent to participate

Not applicable

\section{Consent for publication}

Not applicable

\section{Competing interests}

The authors declare no conflict of interest

\section{Author details}

${ }^{1}$ Oil Crops Research Institute of the Chinese Academy of Agricultural Sciences, Key Laboratory of Biology and Genetic Improvement of Oil Crops, Ministry of Agriculture, and Rural Affairs, No.2 Xudong 2nd Road, Wuhan 430062, China. ${ }^{2}$ Humera Agricultural Research Center of Tigray Agricultural Research Institute, Humera, Tigray, Ethiopia. ${ }^{3}$ Laboratoire Campus de Biotechnologies Végétales, Département de Biologie Végétale, Faculté des Sciences et Techniques, Université Cheikh Anta Diop, BP 5005 Dakar-Fann, 10700 Dakar, Senegal. ${ }^{4}$ Laboratory of Genetics, Horticulture and Seed Sciences, Faculty of Agronomic Sciences, University of Abomey-Calavi, 01 BP 526, Cotonou, Republic of Benin. ${ }^{5}$ Département de Mathématiques et Informatique, Faculté des Sciences et Techniques, Université Cheikh Anta Diop, BP 5005 Dakar-Fann, 10700 Dakar, Senegal.

Received: 25 October 2020 Accepted: 17 May 2021

Published online: 22 June 2021

\section{References}

1. Bedigian D. History and lore of sesame in Southwest Asia. Econ Bot. 2004;58(3):329-53.

2. Bedigian D. Systematics and evolution in Sesamum L.(Pedaliaceae), part 1: evidence regarding the origin of sesame and its closest relatives. Webbia. 2015;70(1):1-42.

3. Ashri A. Sesame breeding. Plant Breed Rev. 1989;16:179-228.

4. Bedigian D. Sesame: the genus Sesamum. Boca Raton: CRC Press; 2010.

5. Lee J, Lee Y, Choe E. Effects of sesamol, sesamin, and sesamolin extracted from roasted sesame oil on the thermal oxidation of methyl linoleate. LWT-Food Sci Technol. 2008;41(10):1871-5.

6. Ashakumary L, Rouyer I, Takahashi Y, Ide T, Fukuda N, Aoyama T, et al. Sesamin, a sesame lignan, is a potent inducer of hepatic fatty acid oxidation in the rat. Metabolism. 1999;48(10):1303-13.

7. Balasubramaniyan P, Palaniappan S. Field crops: an overview. Principles and practices of agronomy. Agrobios, India, 47; 2001.

8. Alegbejo M, Iwo G, Abo M, Idowu A. Sesame: a potential industrial and export oilseed crop in Nigeria. J Sustain Agric. 2003;23(1):59-76.

9. FAOSTAT, F. Statistical databases, fisheries data (2001). Rome: Food and Agriculture Organization of the United Nations; 2018. Available from internet: http://www.fao.org url http://www.fao.org

10. Ashri A. Sesame breeding. Plant Breed Rev. 1998;16:179-228.

11. Dossa K, Diouf D, Wang L, Wei X, Zhang Y, Niang M, et al. The emerging oilseed crop Sesamum indicum enters the "Omics" era. Front Plant Sci. 2017;8:1154.

12. Weiss E. Castor, sesame and safflower; 1971.

13. Varshney RK, Ribaut J-M, Buckler ES, Tuberosa R, Rafalski JA, Langridge P. Can genomics boost productivity of orphan crops? Nat Biotechnol. 2012;30(12):1172-6.

14. Wang L, Yu S, Tong C, Zhao Y, Liu Y, Song C, et al. Genome sequencing of the high oil crop sesame provides insight into oil biosynthesis. Genome Biol. 2014;15(2):1-13.

15. Wei X, Liu K, Zhang Y, Feng Q, Wang L, Zhao Y, et al. Genetic discovery for oil production and quality in sesame. Nat Commun. 2015;6:8609.

16. Huang $X$, Han B. Natural variations and genome-wide association studies in crop plants. Annu Rev Plant Biol. 2014;65:531-51.

17. Wen Y-J, Zhang H, Ni Y-L, Huang B, Zhang J, Feng J-Y, et al. Methodological implementation of mixed linear models in multi-locus genomewide association studies. Brief Bioinform. 2018;19(4):700-12.

18. Cubry P, Pidon H, Ta KN, Tranchant-Dubreuil C, Thuillet A-C, Holzinger M, et al. Genome wide association study pinpoints key agronomic QTLs in African rice Oryza glaberrima. bioRxiv. 2020.

19. Huang X, Sang T, Zhao Q, Feng Q, Zhao Y, Li C, et al. Genome-wide association studies of 14 agronomic traits in rice landraces. Nat Genet. 2010;42(11):961.

20. Li P, Zhou H, Yang H, Xia D, Liu R, Sun P, et al. Genome-wide association studies reveal the genetic basis of fertility restoration of CMS-WA and CMS-HL in xian/indica and aus accessions of rice (Oryza sativa L.). Rice. 2020;13(1):11. 
21. Yano K, Yamamoto E, Aya K, Takeuchi H, Lo P-c, Hu L, et al. Genomewide association study using whole-genome sequencing rapidly identifies new genes influencing agronomic traits in rice. Nat Genet. 2016;48(8):927.

22. Hufford MB, Xu X, Van Heerwaarden J, Pyhäjärvi T, Chia J-M, Cartwright RA, et al. Comparative population genomics of maize domestication and improvement. Nat Genet. 2012;44(7):808-11.

23. Jiao Y, Zhao H, Ren L, Song W, Zeng B, Guo J, et al. Genome-wide genetic changes during modern breeding of maize. Nat Genet. 2012;44(7):812-5.

24. Alves ML, Carbas B, Gaspar D, Paulo M, Brites C, Mendes-Moreira P, et al. Genome-wide association study for kernel composition and flour pasting behavior in wholemeal maize flour. BMC Plant Biol. 2019;19(1):123.

25. Mazaheri M, Heckwolf M, Vaillancourt B, Gage JL, Burdo B, Heckwolf S, et al. Genome-wide association analysis of stalk biomass and anatomical traits in maize. BMC Plant Biol. 2019;19(1):1-17.

26. Lin M, Matschi S, Vasquez M, Chamness J, Kaczmar N, Baseggio M, et al. Genome-wide association study for maize leaf cuticular conductance identifies candidate genes involved in the regulation of cuticle development. G3 Genes Genomes Genetics. 2020;10(5):1671-83.

27. Morris GP, Ramu P, Deshpande SP, Hash CT, Shah T, Upadhyaya HD, et al. Population genomic and genome-wide association studies of agroclimatic traits in sorghum. Proc Natl Acad Sci. 2013;110(2):453-8.

28. Tao Y, Zhao X, Wang X, Hathorn A, Hunt C, Cruickshank AW, et al. Largescale GWAS in sorghum reveals common genetic control of grain size among cereals. Plant Biotechnol J. 2020;18(4):1093-105.

29. Kimani W, Zhang L-M, Wu X-Y, Hao H-Q, Jing H-C. Genome-wide association study reveals that different pathways contribute to grain quality variation in sorghum (Sorghum bicolor). BMC Genomics. 2020;21(1):112

30. Lu F, Romay MC, Glaubitz JC, Bradbury PJ, Elshire RJ, Wang T, et al. Highresolution genetic mapping of maize pan-genome sequence anchors. Nat Commun. 2015;6(1):1-8.

31. Raman H, Raman R, Qiu Y, Yadav AS, Sureshkumar S, Borg L, et al. GWAS hints at pleiotropic roles for FLOWERING LOCUS T in flowering time and yield-related traits in canola. BMC Genomics. 2019;20(1):636.

32. Lu K, Wei L, Li X, Wang Y, Wu J, Liu M, et al. Whole-genome resequencing reveals Brassica napus origin and genetic loci involved in its improvement. Nat Commun. 2019;10(1):1-12.

33. Li D, Dossa K, Zhang Y, Wei X, Wang L, Zhang Y, et al. GWAS uncovers differential genetic bases for drought and salt tolerances in sesame at the germination stage. Genes. 2018;9(2):87.

34. Zhou R, Dossa K, Li D, Yu J, You J, Wei X, et al. Genome-wide association studies of 39 seed yield-related traits in sesame (Sesamum indicum L.). Int J Mol Sci. 2018;19(9):2794.

35. Dossa K, Li D, Zhou R, Yu J, Wang L, Zhang Y, et al. The genetic basis of drought tolerance in the high oil crop Sesamum indicum. Plant Biotechnol J. 2019;17(9):1788-803.

36. He Q, Xu F, Min M-H, Chu S-H, Kim K-W, Park Y-J. Genome-wide association study of vitamin $E$ using genotyping by sequencing in sesame (Sesamum indicum). Genes Genomics. 2019;41(9):1085-93.

37. Challa S, Neelapu NR. Genome-wide association studies (GWAS) for abiotic stress tolerance in plants. In: Biochemical, physiological and molecular avenues for combating abiotic stress tolerance in plants. Amsterdam: Elsevier; 2018. p. 135-50.

38. Rahaman M, Mamidi S, Rahman M. Genome-wide association study of heat stress-tolerance traits in spring-type Brassica napus L. under controlled conditions. Crop J. 2018;6(2):115-25.

39. Wang L, Xia Q, Zhang Y, Zhu X, Zhu X, Li D, et al. Updated sesame genome assembly and fine mapping of plant height and seed coat color QTLs using a new high-density genetic map. BMC Genomics. 2016;17(1):31.

40. Pritchard JK, Stephens M, Donnelly P. Inference of population structure using multilocus genotype data. Genetics. 2000;155(2):945-59.

41. Yu J, Pressoir G, Briggs WH, Bi IV, Yamasaki M, Doebley JF, et al. A unified mixed-model method for association mapping that accounts for multiple levels of relatedness. Nat Genet. 2006;38(2):203-8.

42. Gupta PK, Kulwal PL, Jaiswal V. Association mapping in crop plants: opportunities and challenges. In: Advances in genetics. Amsterdam: Elsevier; 2014. p. 109-47.
43. Widmer C, Lippert C, Weissbrod O, Fusi N, Kadie C, Davidson R, et al. Further improvements to linear mixed models for genome-wide association studies. Sci Rep. 2014;4(1):1-13.

44. Lipka AE, Tian F, Wang Q, Peiffer J, Li M, Bradbury PJ, et al. GAPIT: genome association and prediction integrated tool. Bioinformatics. 2012;28(18):2397-9.

45. Kang HM, Zaitlen NA, Wade CM, Kirby A, Heckerman D, Daly MJ, et al. Efficient control of population structure in model organism association mapping. Genetics. 2008;178(3):1709-23.

46. Zhang Z, Ersoz E, Lai C-Q, Todhunter RJ, Tiwari HK, Gore MA, et al. Mixed linear model approach adapted for genome-wide association studies. Nat Genet. 2010;42(4):355-60.

47. Wang S-B, Feng J-Y, Ren W-L, Huang B, Zhou L, Wen Y-J, et al. Improving power and accuracy of genome-wide association studies via a multilocus mixed linear model methodology. Sci Rep. 2016;6:19444.

48. Buzdugan L, Kalisch M, Navarro A, Schunk D, Fehr E, Bühlmann P. Assessing statistical significance in multivariable genome wide association analysis. Bioinformatics. 2016;32(13):1990-2000.

49. Bush WS, Moore JH. Genome-wide association studies. PLoS Comput Biol. 2012;8(12):e1002822.

50. Tamba CL, Ni Y-L, Zhang Y-M. Iterative sure independence screening EM-Bayesian LASSO algorithm for multi-locus genome-wide association studies. PLoS Comput Biol. 2017;13(1):e1005357.

51. Gawenda I, Thorwarth P, Günther T, Ordon F, Schmid KJ. Genomewide association studies in elite varieties of German winter barley using single-marker and haplotype-based methods. Plant Breed. 2015:134(1):28-39.

52. Abed A, Belzile F. Comparing single-SNP, multi-SNP, and haplotypebased approaches in association studies for major traits in Barley. Plant Genome. 2019;12(3):1-14.

53. Bansal V, Libiger O, Torkamani A, Schork NJ. Statistical analysis strategies for association studies involving rare variants. Nat Rev Genet. 2010;11(11):773-85.

54. Li C, Fu Y, Sun R, Wang Y, Wang Q. Single-locus and multi-locus genome-wide association studies in the genetic dissection of fiber quality traits in upland cotton (Gossypium hirsutum L.). Front Plant Sci. 2018;9:1083.

55. Cui Y, Zhang F, Zhou Y. The application of multi-locus GWAS for the detection of salt-tolerance loci in rice. Front Plant Sci. 2018;9:1464.

56. Li J, Tang W, Zhang Y-W, Chen K-N, Wang C, Liu Y, et al. Genome-wide association studies for five forage quality-related traits in Sorghum (Sorghum bicolor L.). Front Plant Sci. 2018;9:1146.

57. Segura V, Vilhjálmsson BJ, Platt A, Korte A, Seren Ü, Long Q, et al. An efficient multi-locus mixed-model approach for genome-wide association studies in structured populations. Nat Genet. 2012;44(7):825.

58. Ren W-L, Wen Y-J, Dunwell JM, Zhang Y-M. pKWmEB: integration of Kruskal-Wallis test with empirical Bayes under polygenic background control for multi-locus genome-wide association study. Heredity. 2018;120(3):208-18.

59. Zhang Y, Liu P, Zhang X, Zheng Q, Chen M, Ge F, et al. Multi-locus genome-wide association study reveals the genetic architecture of stalk lodging resistance-related traits in maize. Front Plant Sci. 2018;9:611.

60. Gupta PK, Kulwal PL, Jaiswal V. Association mapping in plants in the post-GWAS genomics era. In: Advances in genetics. Amsterdam: Elsevier; 2019. p. 75-154.

61. Klasen JR, Barbez E, Meier L, Meinshausen N, Bühlmann P, Koornneef M, et al. A multi-marker association method for genome-wide association studies without the need for population structure correction. Nat Commun. 2016;7(1):1-8.

62. Zhang J, Feng J, Ni Y, Wen Y, Niu Y, Tamba C, et al. pLARmEB: integration of least angle regression with empirical Bayes for multilocus genomewide association studies. Heredity. 2017;118(6):517-24.

63. Tamba CL, Zhang Y-M. A fast mrMLM algorithm for multi-locus genome-wide association studies. biorxiv. 2018:341784.

64. Ayers KL, Cordell HJ. SNP selection in genome-wide and candidate gene studies via penalized logistic regression. Genet Epidemiol. 2010;34(8):879-91.

65. Cordell HJ, Clayton DG. A unified stepwise regression procedure for evaluating the relative effects of polymorphisms within a gene using case/control or family data: application to HLA in type 1 diabetes. Am J Hum Genet. 2002;70(1):124-41. 
66. Korte A, Vilhjálmsson BJ, Segura V, Platt A, Long Q, Nordborg M. A mixed-model approach for genome-wide association studies of correlated traits in structured populations. Nat Genet. 2012;44(9):1066-71.

67. Turley P, Walters RK, Maghzian O, Okbay A, Lee JJ, Fontana MA, et al. Multi-trait analysis of genome-wide association summary statistics using MTAG. Nat Genet. 2018;50(2):229-37.

68. Zhan X, Zhao N, Plantinga A, Thornton TA, Conneely KN, Epstein $M P$, et al. Powerful genetic association analysis for common or rare variants with high-dimensional structured traits. Genetics. 2017;206(4):1779-90.

69. Ma L, Liu M, Yan Y, Qing C, Zhang X, Zhang Y, et al. Genetic dissection of maize embryonic callus regenerative capacity using multi-locus genome-wide association studies. Front Plant Sci. 2018;9:561.

70. Xu Y, Yang T, Zhou Y, Yin S, Li P, Liu J, et al. Genome-wide association mapping of starch pasting properties in maize using single-locus and multi-locus models. Front Plant Sci. 2018:9:1311.

71. Su J, Ma Q, Li M, Hao F, Wang C. Multi-locus genome-wide association studies of fiber-quality related traits in Chinese early-maturity upland cotton. Front Plant Sci. 2018;9:1169.

72. Chang F, Guo C, Sun F, Zhang J, Wang Z, Kong J, et al. Genome-wide association studies for dynamic plant height and number of nodes on the main stem in summer sowing soybeans. Front Plant Sci. 2018:9:1184.

73. Peng Y, Liu H, Chen J, Shi T, Zhang C, Sun D, et al. Genome-wide association studies of free amino acid levels by six multi-locus models in bread wheat. Front Plant Sci. 2018;9:1196.

74. Gan X, Stegle O, Behr J, Steffen JG, Drewe P, Hildebrand KL, et al. Multiple reference genomes and transcriptomes for Arabidopsis thaliana. Nature. 2011;477(7365):419-23.

75. Goff SA, Ricke D, Lan T-H, Presting G, Wang R, Dunn M, et al. A draft sequence of the rice genome (Oryza sativa L. ssp. japonica). Science. 2002;296(5565):92-100.

76. International, R.G.S.P. The map-based sequence of the rice genome. Nature. 2005:436(7052):793.

77. Yu J, Hu S, Wang J, Wong GK-S, Li S, Liu B, et al. A draft sequence of the rice genome (Oryza sativa L. ssp. indica). Science. 2002;296(5565):79-92.

78. Paterson AH, Bowers JE, Bruggmann R, Dubchak I, Grimwood J, Gundlach $\mathrm{H}$, et al. The Sorghum bicolor genome and the diversification of grasses. Nature. 2009;457(7229):551-6.

79. Schnable PS, Ware D, Fulton RS, Stein JC, Wei F, Pasternak S, et al. The B73 maize genome: complexity, diversity, and dynamics. Science. 2009:326(5956):1112-5.

80. Wang $X$, Wang H, Wang J, Sun R, Wu J, Liu S, et al. The genome of the mesopolyploid crop species Brassica rapa. Nat Genet. 2011:43(10):1035-9.

81. Consortium, I.B.G.S. A physical, genetic and functional sequence assembly of the barley genome. Nature. 2012;491(7426):711-6.

82. Mayer KF, Martis M, Hedley PE, Šimková H, Liu H, Morris JA, et al. Unlocking the barley genome by chromosomal and comparative genomics. Plant Cell. 2011;23(4):1249-63.

83. Zhang G, Liu X, Quan Z, Cheng S, Xu X, Pan S, et al. Genome sequence of foxtail millet (Setaria italica) provides insights into grass evolution and biofuel potential. Nat Biotechnol. 2012;30(6):549-54

84. Consortium PGS. Genome sequence and analysis of the tuber crop potato. Nature. 2011:475(7355):189.

85. Consortium TG. The tomato genome sequence provides insights into fleshy fruit evolution. Nature. 2012;485(7400):635.

86. Tao Y, Zhao X, Mace E, Henry R, Jordan D. Exploring and exploiting pangenomics for crop improvement. Mol Plant. 2019;12(2):156-69.

87. Tettelin H, Masignani V, Cieslewicz MJ, Donati C, Medini D, Ward NL, et al. Genome analysis of multiple pathogenic isolates of Streptococcus agalactiae: implications for the microbial "pan-genome". Proc Natl Acad Sci. 2005;102(39):13950-5.

88. Wang W, Mauleon R, Hu Z, Chebotarov D, Tai S, Wu Z, et al. Genomic variation in 3,010 diverse accessions of Asian cultivated rice. Nature. 2018;557(7703):43-9.

89. Zhao $Q$, Feng $Q$, Lu H, Li Y, Wang A, Tian $Q$, et al. Pan-genome analysis highlights the extent of genomic variation in cultivated and wild rice. Nat Genet. 2018;50(2):278-84

90. Gage JL, Vaillancourt B, Hamilton JP, Manrique-Carpintero NC, Gustafson TJ, Barry K, et al. Multiple maize reference genomes impact the identification of variants by genome-wide association study in a diverse inbred panel. Plant Genome. 2019;12(2):1-12.

91. Li Y-H, Zhou G, Ma J, Jiang W, Jin L-G, Zhang Z, et al. De novo assembly of soybean wild relatives for pan-genome analysis of diversity and agronomic traits. Nat Biotechnol. 2014;32(10):1045-52.

92. Hurgobin B, Golicz AA, Bayer PE, Chan CKK, Tirnaz S, Dolatabadian A, et al. Homoeologous exchange is a major cause of gene presence/ absence variation in the amphidiploid Brassica napus. Plant Biotechnol J. 2018;16(7):1265-74.

93. Montenegro JD, Golicz AA, Bayer PE, Hurgobin B, Lee H, Chan CKK, et al. The pangenome of hexaploid bread wheat. Plant J. 2017;90(5):1007-13.

94. Yu J, Golicz AA, Lu K, Dossa K, Zhang Y, Chen J, et al. Insight into the evolution and functional characteristics of the pan-genome assembly from sesame landraces and modern cultivars. Plant Biotechnol J. 2019;17(5):881-92.

95. Contreras-Moreira B, Cantalapiedra CP, García-Pereira MJ, Gordon SP, Vogel JP, Igartua E, et al. Analysis of plant pan-genomes and transcriptomes with GET_HOMOLOGUES-EST, a clustering solution for sequences of the same species. Front Plant Sci. 2017:8:184.

96. Song J-M, Guan Z, Hu J, Guo C, Yang Z, Wang S, et al. Eight high-quality genomes reveal pan-genome architecture and ecotype differentiation of Brassica napus. Nat Plants. 2020;6(1):34-45.

97. Zhao J, Bayer PE, Ruperao P, Saxena RK, Khan AW, Golicz AA, et al. Trait associations in the pangenome of pigeon pea (Cajanus cajan). Plant Biotechnol J. 2020;18(9):1946-54.

98. Asghar A, Majeed MN. Chemical characterization and fatty acid profile of different sesame verities in Pakistan. Am J Sci Ind Res. 2013:4:540-5.

99. Baydar H. Breeding for the improvement of the ideal plant type of sesame. Plant Breed. 2005;124(3):263-7.

100. Kobayashi T, Kinoshita M, Hattori S, Ogawa T, Tsuboi Y, Ishida M, et al. Development of the sesame metallic fuel performance code. Nucl Technol. 1990;89(2):183-93.

101. Kobayashi T. Cytogenetics of sesame (Sesamum indicum). In: Developments in plant genetics and breeding. Amsterdam: Elsevier; 1991. p. 581-92.

102. Nayar NM, Mehra K. Sesame: its uses, botany, cytogenetics, and origin. Econ Bot. 1970:20-31.

103. Pham TD, Thi Nguyen T-D, Carlsson AS, Bui TM. Morphological evaluation of sesame ('Sesamum indicum'L.) varieties from different origins. Aust J Crop Sci. 2010:4(7):498.

104. Wei W, Zhang Y, Wang L, Li D, Gao Y, Zhang X. Genetic diversity, population structure, and association mapping of 10 agronomic traits in sesame. Crop Sci. 2016;56(1):331-43.

105. Wei X, Gong H, Yu J, Liu P, Wang L, Zhang Y, et al. SesameFG: an integrated database for the functional genomics of sesame. Sci Rep. 2017:7(1):1-10

106. Zhang Y, Zhang X, Che Z, Wang L, Wei W, Li D. Genetic diversity assessment of sesame core collection in China by phenotype and molecular markers and extraction of a mini-core collection. BMC Genet. 2012;13(1):102.

107. Zhang Y-X, Zhang X-R, Hua W, Wang L-H, Che Z. Analysis of genetic diversity among indigenous landraces from sesame (Sesamum indicum L.) core collection in China as revealed by SRAP and SSR markers. Genes Genomics. 2010;32(3):207-15.

108. Dossa K, Wei X, Zhang Y, Fonceka D, Yang W, Diouf D, et al. Analysis of genetic diversity and population structure of sesame accessions from Africa and Asia as major centers of its cultivation. Genes. 2016;7(4):14.

109. Cho Y-I, Park J-H, Lee C-W, Ra W-H, Chung J-W, Lee J-R, et al. Evaluation of the genetic diversity and population structure of sesame (Sesamum indicum L.) using microsatellite markers. Genes Genomics. 2011;33(2):187-95.

110. Yepuri V, Surapaneni M, Kola VSR, Vemireddy L, Jyothi B, Dineshkumar $V$, et al. Assessment of genetic diversity in sesame (Sesamum indicum L.) genotypes, using EST-derived SSR markers. J Crop Sci Biotechnol. 2013;16(2):93-103.

111. Park J-H, Suresh S, Cho G-T, Choi N-G, Baek H-J, Lee C-W, et al. Assessment of molecular genetic diversity and population structure of sesame (Sesamum indicum L.) core collection accessions using simple sequence repeat markers. Plant Genet Resour. 2014;12(1):112-9. 
112. Yue W, Wei L, Zhang T, Li C, Miao H, Zhang H. Genetic diversity and population structure of germplasm resources in sesame (Sesamum indicum L.) by SSR markers. Acta Agron Sin. 2012;38(12):2286-96.

113. Wei W, Zhang Y, Lv H, Wang L, Li D, Zhang X. Population structure and association analysis of oil content in a diverse set of Chinese sesame (Sesamum indicum L.) germplasm. Sci Agric Sin. 2012;45(10):1895-903.

114. Wei W, Zhang Y, Lü H, Li D, Wang L, Zhang X. Association analysis for quality traits in a diverse panel of chinese sesame (Sesamum indicum L.) Germplasm. J Integr Plant Biol. 2013;55(8):745-58.

115. Wu K, Yang M, Liu H, Tao Y, Mei J, Zhao Y. Genetic analysis and molecular characterization of Chinese sesame (Sesamum indicum L.) cultivars using Insertion-Deletion (InDel) and Simple Sequence Repeat (SSR) markers. BMC Genet. 2014;15(1):35.

116. Akbar F, Rabbani MA, Masood MS, Shinwari ZK. Genetic diversity of sesame (Sesamum indicum L.) germplasm from Pakistan using RAPD markers. Pak J Bot. 2011;43(4):2153-60

117. Al-Somain BHA, Migdadi HM, Al-Faif SA, Alghamdi SS, Muharram AA, Mohammed NA, et al. Assessment of genetic diversity of sesame accessions collected from different ecological regions using sequencerelated amplified polymorphism markers. 3 Biotech. 2017;7(1):82.

118. Arriel NHC, Di Mauro AO, Arriel EF, Unêda-Trevisoli SH, Costa MM, Bárbaro IM, et al. Genetic divergence in sesame based on morphological and agronomic traits. Crop Breed Appl Biotechnol. 2007:253-61.

119. Basak M, Uzun B, Yol E. Genetic diversity and population structure of the Mediterranean sesame core collection with use of genomewide SNPs developed by double digest RAD-Seq. PLoS One. 2019;14(10):e0223757.

120. Bedigian D. Evolution of sesame revisited: domestication, diversity and prospects. Genet Resour Crop Evol. 2003;50(7):779-87.

121. Bedigian D, Smyth C, Harlan JR. Patterns of morphological variation inSesamum indicum. Econ Bot. 1986;40(3):353-65.

122. Cui C, Mei H, Liu Y, Zhang H, Zheng Y. Genetic diversity, population structure, and linkage disequilibrium of an association-mapping panel revealed by genome-wide SNP markers in sesame. Front Plant Sci. 2017:8:1189.

123. Dar AA, Mudigunda S, Mittal PK, Arumugam N. Comparative assessment of genetic diversity in Sesamum indicum L. using RAPD and SSR markers. 3 Biotech. 2017;7(1):10.

124. de Sousa Araújo E, Arriel NHC, dos Santos RC, de Lima LM. Assessment of genetic variability in sesame accessions using SSR markers and morpho-agronomic traits. Aust J Crop Sci. 2019;13(1):45.

125. Dossa K, Wei X, Li D, Fonceka D, Zhang Y, Wang L, et al. Insight into the AP2/ERF transcription factor superfamily in sesame and expression profiling of DREB subfamily under drought stress. BMC Plant Biol. 2016:16(1):171.

126. Ercan AG, Taskin M, Turgut $K$. Analysis of genetic diversity in Turkish sesame (Sesamum indicum L.) populations using RAPD markers $\star$. Genet Resour Crop Evol. 2004;51 (6):599-607.

127. Gebremichael DE, Parzies HK. Genetic variability among landraces of sesame in Ethiopia. Afr Crop Sci J. 2011;19(1).

128. Hika G, Geleta N, Jaleta Z. Genetic variability, heritability and genetic advance for the phenotypic traits in sesame (Sesamum indicum L.) populations from Ethiopia. Sci Technol Arts Res J. 2015;4(1):20-6.

129. Pandey SK, Das A, Rai P, Dasgupta T. Morphological and genetic diversity assessment of sesame (Sesamum indicum L.) accessions differing in origin. Physiol Mol Biol Plants. 2015;21(4):519-29.

130. Parsaeian M, Mirlohi A, Saeidi G. Study of genetic variation in sesame (Sesamum indicum L.) using agro-morphological traits and ISSR markers. Russ J Genet. 2011;47(3):314

131. Pham TD, Geleta M, Bui TM, Bui TC, Merker A, Carlsson AS. Comparative analysis of genetic diversity of sesame (Sesamum indicum L.) from Vietnam and Cambodia using agro-morphological and molecular markers. Hereditas. 2011;148(1):28-35.

132. Wei $X$, Wang L, Zhang Y, Qi X, Wang X, Ding $X$, et al. Development of simple sequence repeat (SSR) markers of sesame (Sesamum indicum) from a genome survey. Molecules. 2014;19(4):5150-62.

133. Wei $X$, Zhu X, Yu J, Wang L, Zhang Y, Li D, et al. Identification of sesame genomic variations from genome comparison of landrace and variety. Front Plant Sci. 2016;7:1169.
134. Woldesenbet DT, Tesfaye K, Bekele E. Genetic diversity of sesame germplasm collection (Sesamum indicum L.): implication for conservation, improvement and use. Int J Biotechnol Mol Biol Res. 2015;6(2):7-18.

135. Asekova S, Oh E, Kulkarni KP, Lee MH, Kim Jl, Pae S-B, et al. A combinatorial approach of biparental QTL mapping and genome-wide association analysis identifies candidate genes for phytophthora blight resistance in sesame. bioRxiv. 2020; https://doi.org/10.1101/2020.03.18.996637.

136. Mei H, Cui C, Liu Y, Liu Y, Cui X, Du Z, et al. Genome-wide association study of seed coat color in sesame (Sesamum indicum L.). PLoS One. 2020. https://doi.org/10.21203/rs.2.18296/v2.

137. Xiurong Z, Yingzhong Z, Yong C, Xiangyun F, Qingyuan G, Mingde Z, et al. Establishment of sesame germplasm core collection in China. Genet Resour Crop Evol. 2000;47(3):273-9.

138. Zhang H, Miao H, Wang L, Qu L, Liu H, Wang Q, et al. Genome sequencing of the important oilseed crop Sesamum indicumL. Genome Biol. 2013;14(1):401.

139. Kitts PA, Church DM, Thibaud-Nissen F, Choi J, Hem V, Sapojnikov V, et al. Assembly: a resource for assembled genomes at NCBI. Nucleic Acids Res. 2016;44(D1):D73-80.

140. Wang L, Yu J, Li D, Zhang X. Sinbase: an integrated database to study genomics, genetics and comparative genomics in Sesamum indicum. Plant Cell Physiol. 2015;56(1):e2.

141. Tam V, Patel N, Turcotte M, Bossé Y, Paré G, Meyre D. Benefits and limitations of genome-wide association studies. Nat Rev Genet. 2019:20(8):467-84.

142. Li N, Zheng H, Cui J, Wang J, Liu H, Sun J, et al. Genome-wide association study and candidate gene analysis of alkalinity tolerance in japonica rice germplasm at the seedling stage. Rice. 2019;12(1):24.

143. Zhang P, Zhong K, Zhong Z, Tong H. Genome-wide association study of important agronomic traits within a core collection of rice (Oryza sativa L.). BMC Plant Biol. 2019:19(1):259.

144. Hyten DL, Choi I-Y, Song Q, Shoemaker RC, Nelson RL, Costa JM, et al. Highly variable patterns of linkage disequilibrium in multiple soybean populations. Genetics. 2007;175(4):1937-44.

145. Li M, Liu Y, Tao Y, Xu C, Li X, Zhang X, et al. Identification of genetic loci and candidate genes related to soybean flowering through genome wide association study. BMC Genomics. 2019;20(1):987.

146. Wu Z, Wang B, Chen X, Wu J, King GJ, Xiao Y, et al. Evaluation of linkage disequilibrium pattern and association study on seed oil content in Brassica napus using ddRAD sequencing. PLoS One. 2016;11(1):e0146383.

147. Rashid Z, Singh PK, Vemuri H, Zaidi PH, Prasanna BM, Nair SK. Genomewide association study in Asia-adapted tropical maize reveals novel and explored genomic regions for sorghum downy mildew resistance. Sci Rep. 2018;8(1):1-12.

148. Dossa K, Zhou R, Li D, Liu A, Qin L, Mmadi MA, et al. A novel motif in the 5'-UTR of an orphan gene 'Big Root Biomass' modulates root biomass in sesame. Plant Biotechnol J. 2020. https://doi.org/10.1111/pbi.13531.

149. Su R, Zhou R, Mmadi MA, Li D, Qin L, Liu A, et al. Root diversity in sesame (Sesamum indicum L.): insights into the morphological, anatomical and gene expression profiles. Planta. 2019;250(5):1461-74.

150. Zhang H, Miao H, Wei L, Li C, Zhao R, Wang C. Genetic analysis and QTL mapping of seed coat color in sesame (Sesamum indicum L.). PLoS One. 2013;8(5):e63898.

151. Chowdhury S, Basu A, Kundu S. Overexpression of a new osmotin-like protein gene (SindOLP) confers tolerance against biotic and abiotic stresses in sesame. Front Plant Sci. 2017;8:410.

152. Martins PK, Nakayama TJ, Ribeiro AP, da Cunha BADB, Nepomuceno AL, Harmon FG, et al. Setaria viridis floral-dip: a simple and rapid Agrobacterium-mediated transformation method. Biotechnol Rep. 2015;6:61-3.

153. Gomes C, Dupas A, Pagano A, Grima-Pettenati J, Paiva JAP. Hairy root transformation: a useful tool to explore gene function and expression in Salix spp. recalcitrant to transformation. Front Plant Sci. 2019;10:1427.

\section{Publisher's Note}

Springer Nature remains neutral with regard to jurisdictional claims in published maps and institutional affiliations. 